\title{
Molecular-Level Study of Photo-Orientation in Hydrogen-Bonded Azopolymer Complexes
}

\author{
Xiaoxiao Wang, Jaana Vapaavuori, C. Geraldine Bazuin, and Christian Pellerin* \\ Département de chimie, Université de Montréal, C.P. 6128, Succ. Centre-Ville, Montréal \\ (QC), Canada H3C 3J7
}

\begin{abstract}
To optimize azobenzene-containing materials for applications such as rewritable waveguides and holographic data storage, it is imperative to understand the effect of the azobenzene structure on the photoresponse of the material. Supramolecular materials, in which a complexed photoactive azobenzene controls the motion or other properties of a passive polymer, are uniquely convenient for studying the impact of specific chemical modifications. Here, we use polarization modulation infrared structural absorbance spectroscopy (PM-IRSAS) to hydrogen-bonded supramolecular azobenzene complexes using poly(4-vinylpyridine) (P4VP) as a model polymer. We show that changing the tail group from hydrogen $\left(\mathrm{AH}_{\mathrm{H}}\right)$ to cyano $\left(\mathrm{ACN}_{\mathrm{CN}}\right.$ induces greater angular redistribution of the chromophores and, remarkably, provokes P4VP pyridine ring orientation. Increasing the degree of complexation decreases the saturated orientation of both $A_{H}$ and $A_{C N}$, whereas for $\mathrm{P} 4 \mathrm{VP} / \mathrm{A}_{\mathrm{CN}}$ it increases the pyridine orientation as well as the orientation stability of both components. These results explain the contrasting photoinduced birefringence behavior previously observed for these complexes and identify azo-azo intermolecular interactions as the main reason. To our knowledge, this is the first molecular-level spectroscopic analysis of the contrasting contributions of azobenzenes to the photo-orientation of supramolecular azopolymer complexes and the first report of the large impact of small molecular changes on the capacity of azo dyes to transfer light-induced orientation to a photopassive polymer.
\end{abstract}




\section{INTRODUCTION}

Azobenzene and its derivatives (collectively abbreviated as azo) undergo photoisomerization between trans and cis isomers upon irradiation, a clean and efficient photoreaction that gives rise to various useful phenomena. ${ }^{1,2}$ Among these phenomena, azo molecules that are illuminated with linearly polarized light tend to align with their long axis perpendicular to the polarization of the incident light. This photoinduced orientation is of interest for many optoelectronic and photonic applications, such as surface commanding of liquid crystal displays, ${ }^{3}$ waveguide couplers, ${ }^{4,5}$ and rewritable holographic data storage. ${ }^{6,7}$ Macroscopic motion can also be induced by light in azo-containing materials, ${ }^{1,8,9}$ enabling the design of photosensitive devices like artificial muscles ${ }^{10}$ and light-driven motors. ${ }^{11}$

The majority of azopolymers that have been investigated to date have the azo groups covalently bonded in the main chain, ${ }^{12,13}$ as side chains, ${ }^{1,5-11}$ or even as crosslinks between chains. ${ }^{9,}{ }^{11}$ More recently, supramolecular azo-containing polymers - particularly where an azo molecule is non-covalently attached as an effective side chain to a photopassive polymer host - have been gaining increased attention due to their more easily tailorable material properties and their simpler preparation procedure as compared to the synthesis required for all-covalent polymers. Such complexes have been shown to be efficient in developing photoorientation, typically measured as photoinduced birefringence (PIB), as well as in forming surface relief gratings (SRGs), using supramolecular ionic, ${ }^{14-19}$ hydrogen ${ }^{20-26}$ and halogen ${ }^{27-}$ 29 bonds. In many cases, the passive polymer host employed is poly(4-vinylpyridine) (P4VP). ${ }^{16-21,23-29}$

Various studies have revealed that the chemical structure and the content of the supramolecularly attached azo have significant impact on the measured PIB ${ }^{23-25,30}$ and on SRG formation efficiency. ${ }^{20-22}$ For example, the saturated PIB per azobenzene unit of hydrogen-bonded P4VP-azo complexes, where the azos used differ only by the nature of its tail group (Scheme 1), increases by more than a factor of 2 when increasing azo content for the cyano-tailed azo (CN-tailed or $\mathrm{ACN}_{\mathrm{CN}}$, whereas it decreases by up to a factor of 2 for the hydrogen-tailed azo $\left(\mathrm{H}\right.$-tailed or $\left.\mathrm{A}_{\mathrm{H}}\right){ }^{25}$ 


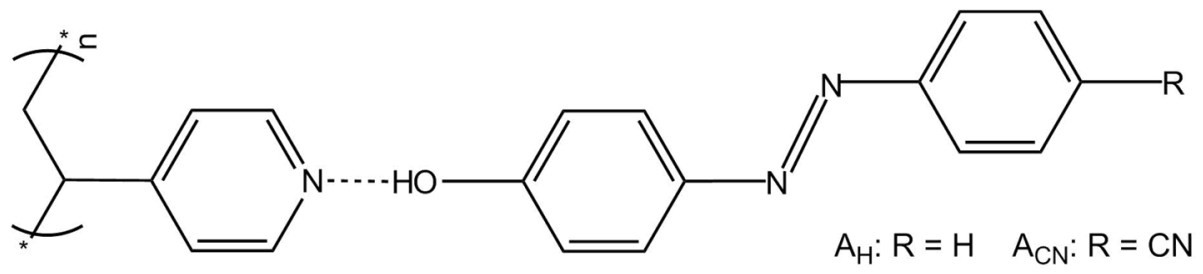

Scheme 1. Supramolecular complexes of poly(4-vinylpyridine) (P4VP) with 4phenylazophenol $\left(A_{H}, R=H\right)$ and 4-hydroxy-4'-cyanoazobenzene $\left(A_{C N}, R=C N\right)$.

To better understand the contrasting photo-orientation behavior in such chemically similar systems, it is desirable to determine the orientation of individual molecular groups, as opposed to the overall orientation determined by birefringence. This can be done by using polarized Fourier transform infrared spectroscopy (FT-IR) techniques because they allow measuring orientation of specific chemical moieties. Static polarized FT-IR has been applied to polymers that are covalently bonded ${ }^{31-37}$ or doped ${ }^{38-40}$ with azobenzenes, but its limited time resolution only allows the kinetics of slow processes to be followed. Buffeteau and Pézolet were the first to use polarization modulation infrared linear dichroism (PM-IRLD), a polarized FT-IR method enabling a time resolution as high as $200 \mathrm{~ms},{ }^{41,42}$ to probe the time-resolved photo-orientation of a Disperse Red 1-containing amorphous azopolymer. ${ }^{43} \mathrm{~A}$ shortcoming of PM-IRLD, however, is that it only measures the dichroic difference $(\Delta A)$ between the spectra polarized parallel $\left(A_{p}\right)$ and perpendicular $\left(A_{s}\right)$ to the laser polarization direction, so that the structural absorbance $\left(A_{0}\right)$ information is missing. Liang et al. later developed a related FT-IR method, called polarization modulation infrared structural absorbance spectroscopy (PM-IRSAS), to overcome this limitation and to improve the accuracy of the calculated orientation parameters. ${ }^{44}$

Here, we employ PM-IRSAS to follow the photo-orientation induced by linearly polarized light and its subsequent thermal relaxation in the two H-bonded supramolecular complexes mentioned above (ACN and $A_{H}$ with P4VP) and depicted in Scheme 1. We will show that the orientation of both $\mathrm{A}_{\mathrm{H}}$ and $\mathrm{A}_{\mathrm{CN}}$ decreases with increasing azo content but that $\mathrm{A}_{\mathrm{CN}}$ orients more than $\mathrm{A}_{\mathrm{H}}$ and is the only one capable of driving photo-induced orientation 
of the passive P4VP pyridine groups through the hydrogen bonds. In addition, we will show that $\mathrm{A}_{\mathrm{H}}$ mainly undergoes angular hole burning, which results from the trans-cis isomerization, whereas for $\mathrm{ACN}_{\mathrm{CN}}$ there is a significant additional contribution from angular redistribution that leads to reorientation of the trans ACN and of their H-bonded pyridine side groups as well as to increased thermal stability of the orientation. This information explains how the differences in tail group of the azo leads to different photo-orientation mechanisms and thus the contrasting birefringence results in ref. 25 .

\section{EXPERIMENTAL}

Materials and Sample Preparation. Poly(4-vinylpyridine) (P4VP) with a viscosity average molecular weight of $200 \mathrm{~kg} / \mathrm{mol}$ was obtained from Scientific Polymer Products. 4Phenylazophenol $\left(\mathrm{A}_{\mathrm{H}}\right.$, 97\%) was purchased from Sigma-Aldrich and 4-hydroxyl-4'cyanoazobenzene $(\mathrm{ACN})$ from Beamco. Chloroform $\left(\mathrm{CHCl}_{3}, \mathrm{HPLC}\right.$ grade) and N,Ndimethylformamide (DMF, 99.8\%) were purchased from EMD and methanol (MeOH, HPLC grade) from Fisher Scientific. All products were used as received.

P4VP was dissolved, with or without azobenzene, in pure $\mathrm{CHCl}_{3}$ (for the most dilute solutions), in a mixed solvent of $\mathrm{CHCl}_{3}$ and $\mathrm{MeOH}$ (for more concentrated solutions, for which the addition of $\mathrm{MeOH}$ facilitated solubilization), or in pure DMF (for UV-visible and birefringence measurements) in $10 \mathrm{~mL}$ vials to give solutions of desired concentrations and P4VP-azobenzene compositions. The solutions in the $\mathrm{CHCl}_{3} / \mathrm{MeOH}$ solvent mixture were prepared by first mixing the solvents at a $6: 1 \mathrm{CHCl}_{3}: \mathrm{MeOH}$ mass ratio, which was then added to the solute, followed by homogenization for $2 \mathrm{~min}$ in an ultrasonic bath (Fisher Scientific FS60). All solutions were shaken gently for 3 days with a Heidolph UNIMAX 1010 shaker (Rose Scientific) to obtain homogeneous samples and were left for 1 day before further use. The composition of the complexes is indicated as $\mathrm{P} 4 \mathrm{VP} / \mathrm{A}_{\mathrm{H}}\left(F_{A}\right)$ and $\mathrm{P} 4 \mathrm{VP} / \mathrm{ACN}_{\mathrm{CN}}\left(F_{A}\right)$, where $F_{A}$ refers to the mole percent of azobenzene molecules relative to the pyridine rings of $\mathrm{P} 4 \mathrm{VP}$. These values, unless otherwise noted, were determined by FT-IR with reference to precisely determined calibration curves (described in detail in section A of the Supporting Information). 
They generally corresponded well (within experimental uncertainty) to the nominal values determined by the measured weights of the components before dissolution.

For static FT-IR characterization, samples were prepared by casting $5 \mu \mathrm{L}$ solutions of $\mathrm{P} 4 \mathrm{VP} / \mathrm{A}_{\mathrm{H}}$ or $\mathrm{P} 4 \mathrm{VP} / \mathrm{ACN}_{\mathrm{CN}}$ in $\mathrm{CHCl}_{3}$, with a $\mathrm{P} 4 \mathrm{VP}$ concentration of $0.1-0.5 \mathrm{wt} \%$, on $\mathrm{BaF}_{2}$ windows, followed by drying in a FTS Systems FD-3-85A-MP freeze-dryer at 1-3 mT and $90{ }^{\circ} \mathrm{C}$ for 15-30 min and then drying under Petri dish covers in a fume hood for 3 days. For PM-IRSAS measurements, samples were prepared by casting $50 \mu \mathrm{L}$ solutions of $\mathrm{P} 4 \mathrm{VP} / \mathrm{A}_{\mathrm{H}}$ or $\mathrm{P} 4 \mathrm{VP} / \mathrm{ACN}$ in $\mathrm{CHCl}_{3} / \mathrm{MeOH}\left(6: 1 \mathrm{CHCl}_{3}: \mathrm{MeOH}\right.$ w:w), at $1 \mathrm{wt} \% \mathrm{P} 4 \mathrm{VP}$ concentration, on $\mathrm{BaF}_{2}$ windows, followed by freeze-drying for 15-30 min and then drying in a fume hood for 5 days.

For UV-vis spectroscopy experiments, the samples were spin-coated from DMF solutions of 2-3 wt\% P4VP concentration on glass substrates cleaned by acetone using varying spincoating speeds $(750 \mathrm{rpm}-2500 \mathrm{rpm})$ to give films of comparable optical density at $488 \mathrm{~nm}$, following which the samples were dried in a fume hood for $24 \mathrm{~h}$. For photoinduced birefringence measurements, the samples were spin-coated from DMF solutions on quartz substrates using speeds of 750-2500 rpm to have a fixed absorbance at $457 \mathrm{~nm}$, followed by drying at $70{ }^{\circ} \mathrm{C}$ for $24 \mathrm{~h} .{ }^{25}$

Measurements. Static FT-IR measurements were performed on a Bruker Optics Vertex 70 spectrometer with a deuterated L-alanine triglycine sulfate (DLATGS) detector. All spectra were obtained with a resolution of $4 \mathrm{~cm}^{-1}$ by averaging 512 scans. PM-IRSAS measurements were recorded with the same spectrometer and the external setup shown in Scheme 2. The optical setup includes a vertically-polarized $488 \mathrm{~nm}$ diode laser (JDSU FCD488-020) with a beam diameter of $0.7 \mathrm{~mm}$ expanded to $7 \mathrm{~mm}$, using a $10 \mathrm{X}$ beam expander (Thorlabs BE10M), to fully cover the IR probe beam and illuminate the sample with an irradiance of $\sim 20 \mathrm{~mW} / \mathrm{cm}^{2}$. This irradiation wavelength can be absorbed by the trans and cis isomers of both $\mathrm{A}_{\mathrm{CN}}$ and $\mathrm{A}_{\mathrm{H}}$ and therefore allows the rapid trans-cis-trans cycling required to photo-orient the materials. ${ }^{16}$ The PM-IRSAS setup includes a liquid-nitrogencooled mercury cadmium telluride (MCT) photovoltaic detector (Kolmar Technologies), two ZnSe lenses, a KRS-5 wire-grid polarizer (Optometrics), and a photoelastic modulator (PEM- 
90 type II/ZS50, Hinds Instruments) operating at $100 \mathrm{kHz}$. The detected signal was processed using a lock-in amplifier (Stanford Research Systems, SR830) with a 30- $\mu$ s time constant and two dual-channel electronic filters (Frequency Devices, 90TP/90IPB) to generate the dichroic difference $(\Delta A)$ and the individual polarized spectra $\left(A_{p}\right.$ and $\left.A_{s}\right)$, following the method described by Liang et al. ${ }^{44}$

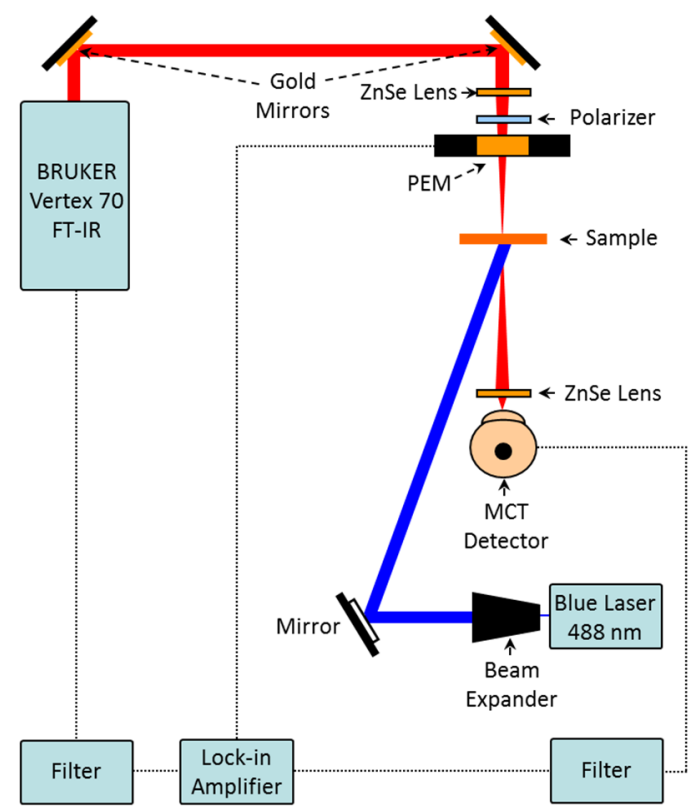

Scheme 2. Experimental setup for the in-situ polarization modulation infrared structural absorbance spectroscopy (PM-IRSAS) study of the photo-orientation of supramolecular azobenzene-containing P4VP complexes.

PM-IRSAS spectra were recorded for $1800 \mathrm{~s}$ during irradiation of samples and for 1600 s during subsequent thermal relaxation. All spectra were obtained with a resolution of $4 \mathrm{~cm}^{-}$ ${ }^{1}$ by averaging 400 scans for the initial state, 20 scans per spectrum for the first 1 min of illumination (laser on) and relaxation (laser off) processes where the changes in orientation are rapid, and 320 scans per spectrum for the slower photostationary/residual relaxation stages. The size of the samples for PM-IRSAS measurements was generally greater than 10 $\mathrm{mm}$ in diameter, much larger than that of the IR beam $(\sim 1 \mathrm{~mm})$, which could thus always be 
positioned so as to avoid the thicker edges of the samples. The variability in the local chemical composition $\left(F_{A}\right)$ was determined for selected compositions from measurements of 2-3 different samples cast from the same solution; this is shown by the error bars in Figure S2. The orientation parameter $\left(<P_{2}>\right)$ was calculated using Eq. 1,

$$
\left\langle P_{2}\right\rangle=\left(\frac{2}{3 \cos ^{2} \alpha-1}\right)\left(\frac{\Delta A}{3 A_{0}}\right)
$$

where $\Delta A$ is the dichroic difference, $A_{0}=\left(A_{p}+2 A_{s}\right) / 3$ is the structural absorbance, and $\alpha$ is the angle between the transition dipole moment of the vibration and the molecular axis of interest. Eq. 1 assumes that the orientation is uniaxial with respect to the laser polarization direction, which is expected to be the case considering the low $\left\langle P_{2}\right\rangle$ values reached in this work. $^{45}$

The UV-vis measurements were performed with a fiber-coupled spectrometer (Ocean Optics, USB 2000+) and a DH-mini light source, combined with the linearly polarized 488 $\mathrm{nm}$ laser to pump the azobenzenes for $5 \mathrm{~min}$. A clean glass substrate was used as the reference. Birefringence was induced by a vertically polarized $457 \mathrm{~nm}$ laser beam with an irradiance of $150 \mathrm{~mW} / \mathrm{cm}^{2}$. Saturated birefringence values were obtained after 75-150 s of irradiation and the residual birefringence values were determined $300 \mathrm{~s}$ after removal of irradiation (see ref. 25 for additional details). Density functional theory (DFT) calculations were performed using the Gaussian 16 software with the B3LYP functional and the 6-311+G(d,p) basis set.

\section{RESULTS AND DISCUSSION}

Before presenting the polarized IR spectroscopy results of photoinduced orientation and relaxation for specific moieties in the $\mathrm{P} 4 \mathrm{VP} / \mathrm{A}_{\mathrm{CN}}$ and $\mathrm{P} 4 \mathrm{VP} / \mathrm{A}_{H}$ azopolymer complexes, we determined the extent of their complexation and trans-cis conversion under illumination to verify if there are any differences in the two series that might account, at least in part, for their contrasting photo-orientation behavior reported in ref. 25 .

Quantification of the Extent of Complexation. Hydrogen bonding between the polymer pyridine groups and the azobenzene hydroxyl groups was confirmed by IR, as 
shown in Figure 1. In particular, the band at $993 \mathrm{~cm}^{-1}$ in the spectrum of pure P4VP, which is due to a deformation vibration of the free pyridine ring, is known to shift to higher frequency upon interaction with H-bond donors. ${ }^{46}$ This is observed in the spectra of the P4VP complexes with both $A_{H}$ and $A_{C N}$, where a new band appears at $1010 \mathrm{~cm}^{-1}$. The fact that the position of this band is identical for both complexes indicates that the hydrogen bond strength is similar for both. The band intensity increases with increase in mole percent of azobenzene relative to the P4VP repeat units $\left(F_{A}\right)$ due to increased H-bonding complexation. However, the $993 \mathrm{~cm}^{-1}$ band remains slightly visible even for the equimolar mixtures, indicating that the level of complexation is very high but not quite complete, as discussed in more detail below.

The extent of complexation $\left(f_{b}\right)$, expressed in terms of the percentage of the pyridine rings that are H-bonded, was calculated by Eq. 2,

$$
f_{b}=\frac{I_{b}}{I_{b}+I_{f} / a} \times 100 \%
$$

where $I_{f}$ and $I_{b}$ are the intensities of the free and H-bonded pyridine bands at 993 and 1010 $\mathrm{cm}^{-1}$, respectively, and $a$ is the ratio of their absorption coefficients. Because of partial overlap between the P4VP bands and bands due to the azobenzene (for example, the $\mathrm{A}_{\mathrm{H}}$ band at $1019 \mathrm{~cm}^{-1}$ ), a second-derivative method was used to obtain $I_{b}$ and $I_{f}$. The parameter $a$ in Eq. 2 was determined as 0.39 and 0.35 for $\mathrm{P} 4 \mathrm{VP} / \mathrm{AcN}$ and $\mathrm{P} 4 \mathrm{VP} / \mathrm{AH}$, respectively, following a method we developed previously. ${ }^{46}$ Details concerning the determination of $f_{b}$ are provided in the Supporting Information (section B) and the values are plotted in Figure 2 as a function of $F_{A}$. 

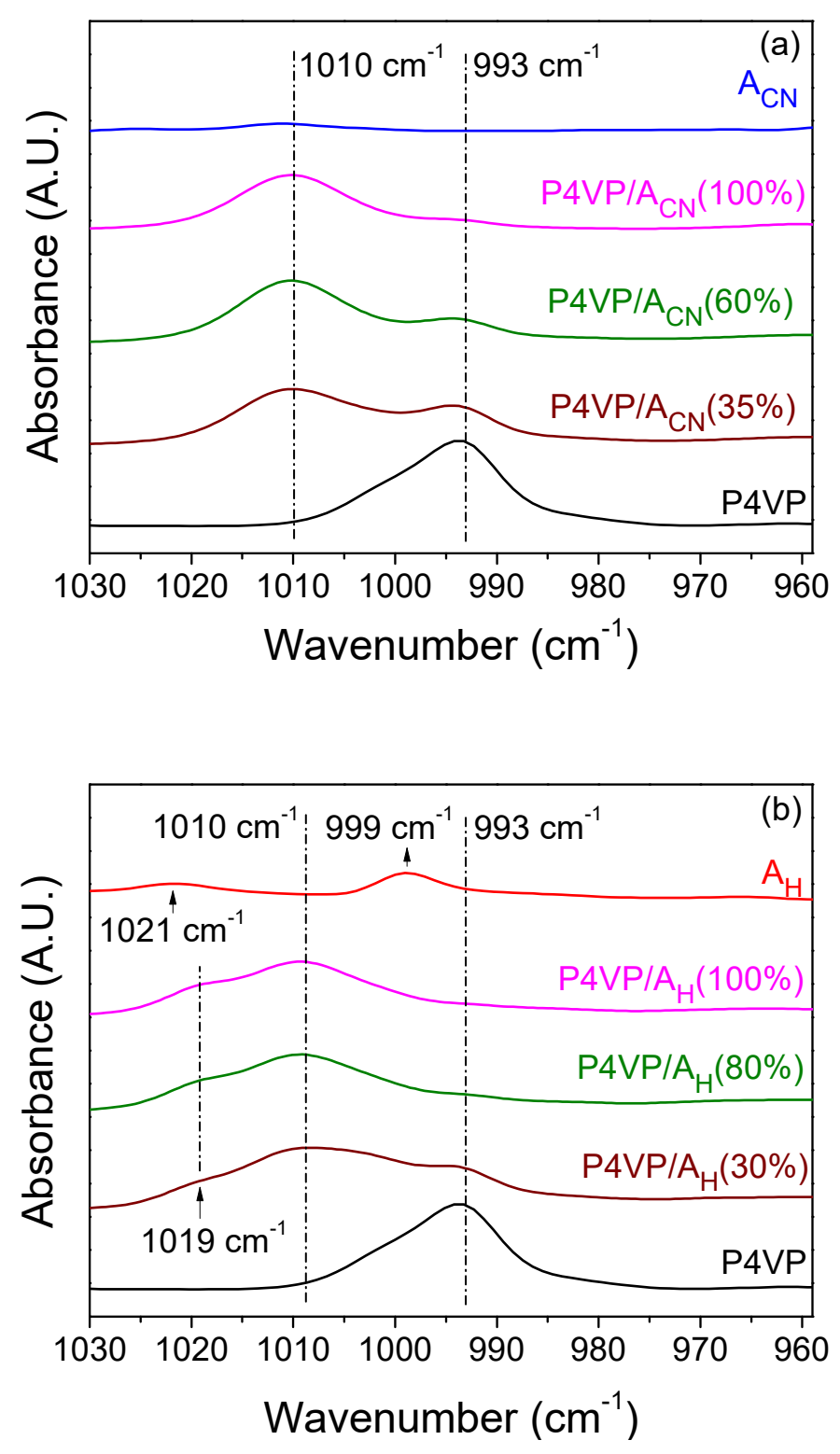

Figure 1. Infrared spectra of a pure P4VP film, of the pure azobenzene crystalline powder, and of drop-cast films of the P4VP complexes containing (a) $A_{C N}$ and (b) $A_{H}$ of the approximate azo mole percentages with respect to the pyridine units $\left(F_{A}\right)$ indicated. The azocontaining spectra were normalized with respect to the $1140 \mathrm{~cm}^{-1}$ azo band. 
Figure 2 shows that $f_{b}$ increases with $F_{A}$ similarly for both complexes. Although the degree of complexation of the chromophores to P4VP is high, this plot indicates that, on average, it is about $20 \%$ below that expected from full complexation (indicated by the dashed line). If not due to a hidden systematic error, this suggests that there is some kind of kinetic limitation to $\mathrm{OH}$-pyridine complexation that might reflect a solution equilibrium involving hydrogen bonding between azo and solvent that is not fully reequilibrated in the film due to rapid solvent evaporation and restricted P4VP chain mobility (considering the $T_{g}$ of $142{ }^{\circ} \mathrm{C}$ for pure P4VP). ${ }^{25,46,47}$ Most importantly, the different chemical structures of $\mathrm{P} 4 \mathrm{VP} / \mathrm{A}_{\mathrm{H}}$ and $\mathrm{P} 4 \mathrm{VP} / \mathrm{A}_{\mathrm{CN}}$ clearly do not affect the extent of complexation, excluding it as the origin of their contrasting photo-orientation behavior mentioned in the Introduction. ${ }^{24,25}$

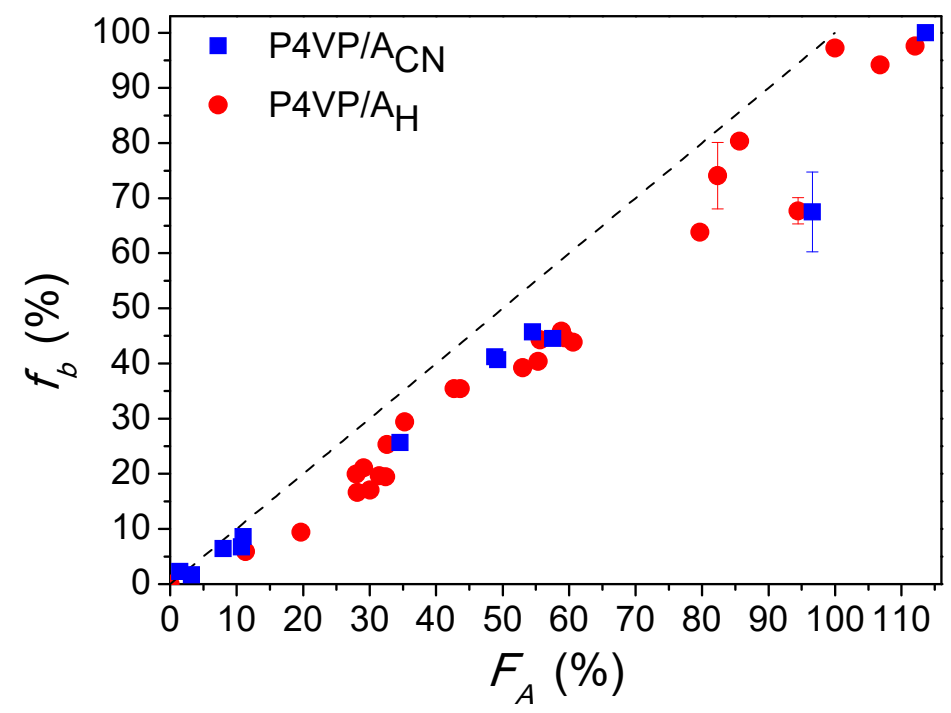

Figure 2. Percentage of H-bonded pyridine rings, $f_{b}$, as a function of mole percent azobenzene relative to pyridine, $F_{A}$, for $\mathrm{P} 4 \mathrm{VP} / \mathrm{A}_{\mathrm{CN}}$ and $\mathrm{P} 4 \mathrm{VP} / \mathrm{A}_{\mathrm{H}}$ complexes. The dashed line depicts the theoretical values for full complexation of the azobenzenes to P4VP. Representative error bars are based on measurements of 3 samples per point.

Trans/Cis Content under Illumination. Figure 3 shows the UV-vis spectra of $\mathrm{P} 4 \mathrm{VP} / \mathrm{ACN}_{\mathrm{CN}}$ and $\mathrm{P} 4 \mathrm{VP} / \mathrm{A}_{\mathrm{H}}$ films with different $F_{A}$ before and immediately after 5 min of irradiation with $488 \mathrm{~nm}$ light. The spectra feature an intense band attributed to $\pi$ - 
$\pi *$ absorption of the trans isomer. ${ }^{35,48}$ The maximum absorption $\left(\lambda_{\max }\right)$ is located at $377 \mathrm{~nm}$ for P4VP/ACN films and $360 \mathrm{~nm}$ for P4VP/Aн films with low $\mathrm{F}_{\mathrm{A}}$ (less than 10\%), where azoazo interactions are expected to be limited. These band positions are indeed similar to those measured for the pure azos in dilute DMF solutions. ${ }^{25}$ The band shifts to lower wavelengths with increasing $F_{A}$ (as indicated by the arrows), indicating increased chromophore excitonic coupling and $\pi-\pi$ interactions in the complexes with higher $F_{A}{ }^{49}$ The effect of $F_{A}$ is significantly greater for P4VP/ACN (blue shift of about $28 \mathrm{~nm}$ ) than for P4VP/AH (about 11 $\mathrm{nm})$, which is consistent with the much higher dipole moment calculated for AcN (6.8 D) compared to $\mathrm{A}_{\mathrm{H}}(1.6 \mathrm{D})$ and indicates stronger intermolecular interactions between the $\mathrm{A}_{\mathrm{CN}}$. The latter also lead to a liquid crystalline state for $\mathrm{P} 4 \mathrm{VP} / \mathrm{A}_{\mathrm{CN}}$ when $F_{A}$ is greater than about $35 \%$, whereas $\mathrm{P} 4 \mathrm{VP} / \mathrm{A}_{\mathrm{H}}$ remains isotropic (non birefringent) even for $100 \% F_{A}{ }^{25}$

During irradiation with $488 \mathrm{~nm}$ light, the intensity of the $\pi-\pi *$ band decreases for both $\mathrm{P} 4 \mathrm{VP} / \mathrm{A}_{\mathrm{CN}}$ and $\mathrm{P} 4 \mathrm{VP} / \mathrm{A}_{\mathrm{H}}$ (dashed spectra) with no change in $\lambda_{\max }$, indicating that trans-cis isomerization occurs and that the chromophore-chromophore interactions of azos remaining in the trans state are not affected by the isomerization. ${ }^{35,48}$ After 5 min of illumination, the $\mathrm{n}-\pi *$ absorption of the cis isomer appears as a very weak band near $460 \mathrm{~nm}$ for $\mathrm{P} 4 \mathrm{VP} / \mathrm{A}_{\mathrm{H}}{ }^{50}$ and near $480 \mathrm{~nm}$ for $\mathrm{P} 4 \mathrm{VP} / \mathrm{A}_{\mathrm{CN}}$. The decrease in intensity of the $\pi-\pi *$ bands after illumination can be used to calculate the loss of trans isomer, and thus minimal cis isomer values, which for both complexes are $6-7 \%$ when $F_{A}$ is $100 \%$ and $11-13 \%$ when $F_{A}$ is less than $10 \%$ (see Figure S6 in section C of the Supporting Information). The decrease in photoisomerization efficiency at higher $F_{A}$ is related to decreased free volume around the azobenzene molecules. Most importantly, Figure S6 further shows that the trans isomer content after illumination is almost identical for both complexes, thus also eliminating this factor as an explanation for their contrasting photoresponse. 

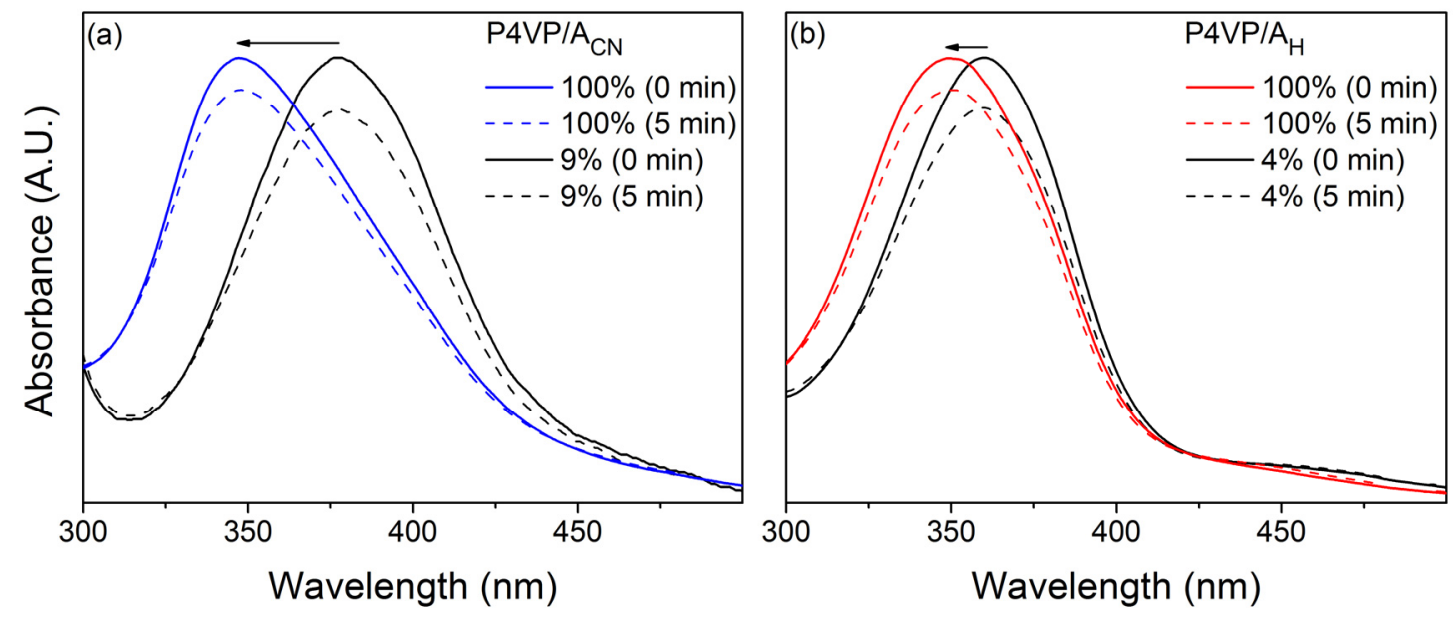

Figure 3. Normalized UV-Vis spectra of (a) P4VP/ACN and (b) $\mathrm{P} 4 \mathrm{VP} / \mathrm{A}_{H}$ with the specified nominal $F_{A}$, before irradiation ( $0 \mathrm{~min}$, solid lines) and after $5 \mathrm{~min}$ of irradiation (dashed lines).

Polarized Infrared Spectral Analysis. Figure 4 shows the dichroic difference $(\Delta A)$ and the structural absorbance $\left(A_{0}\right)$ infrared spectra of the two types of complexes $\left(F_{A}=100 \%\right)$ after $1800 \mathrm{~s}$ of irradiation, in comparison with the spectra of the pure components. Many negative bands appear in the $\Delta A$ spectra, indicating that the groups associated with these bands have undergone photo-orientation and that their transition dipole moments are oriented perpendicularly to the laser polarization. To compare the photo-orientation of the azo and polymer, the orientation parameter, $\left\langle P_{2}>\right.$, of appropriate bands must be quantified using Eq. 1. Ideally, the selected bands should be isolated in both the $A_{0}$ and $\Delta A$ spectra to avoid contributions from more than one component. In addition, they should be of sufficient intensity to provide an acceptable signal-to-noise ratio for dynamic studies. 

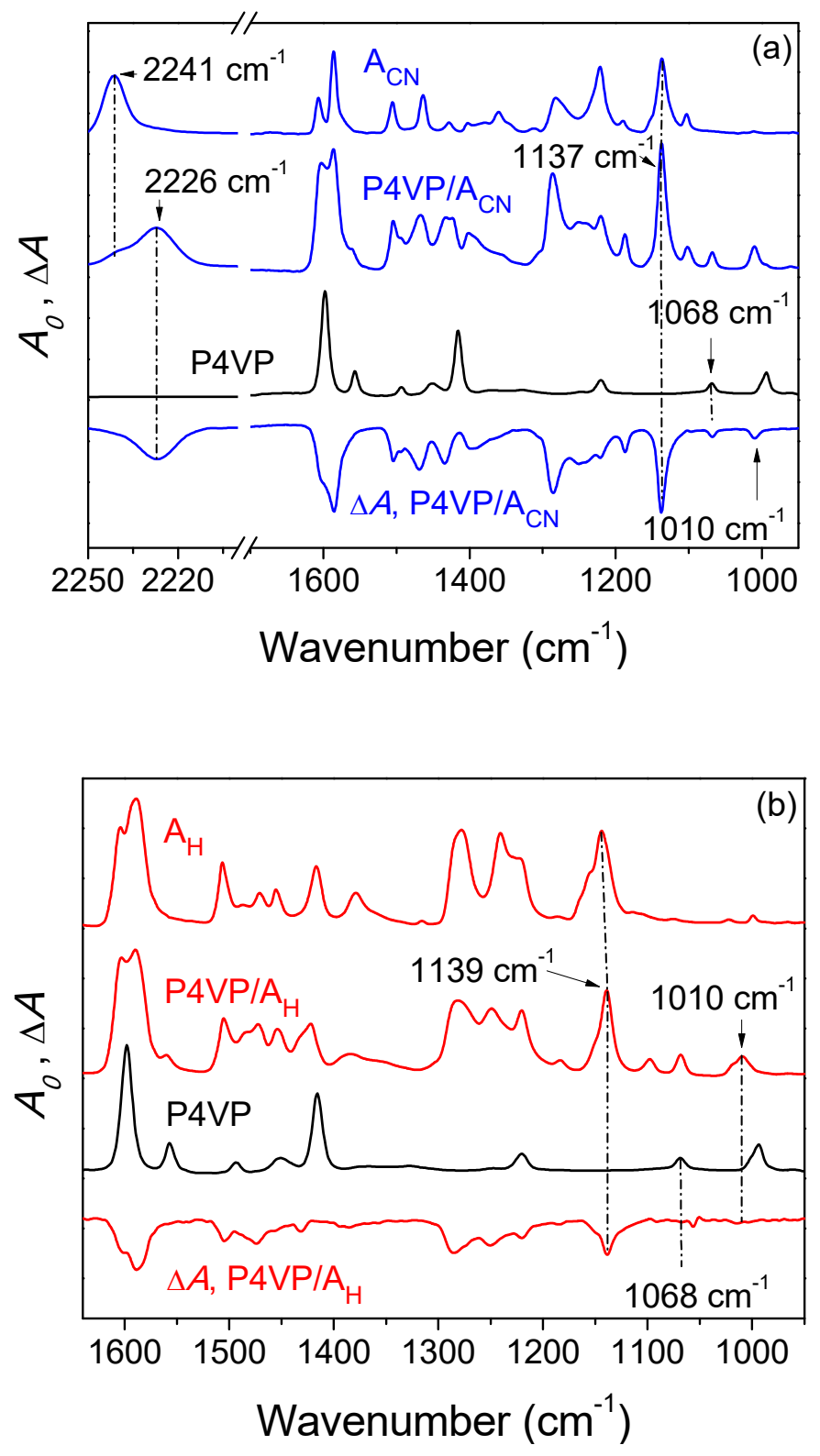

Figure 4. Infrared structural absorbance spectra ( $A_{0}$ for all unspecified curves) and dichroic difference spectra $(\Delta A)$ of (a) $\mathrm{P} 4 \mathrm{VP} / \mathrm{A}_{\mathrm{CN}}(100 \%)$ and (b) $\mathrm{P} 4 \mathrm{VP} / \mathrm{A}_{\mathrm{H}}(100 \%)$ after $1800 \mathrm{~s}$ of irradiation. The spectra of pure P4VP powder (black) and pure azobenzene crystalline powders (blue for $\mathrm{ACN}_{\mathrm{CN}}$ and red for $\mathrm{AH}_{\mathrm{H}}$ ) are shown to highlight the isolated bands used for quantifying the molecular orientation. 
For the azo, the bands at 1137 and $1139 \mathrm{~cm}^{-1}$ for $A_{C N}$ and $A_{H}$, respectively, which are assigned to a symmetric $\mathrm{C}-\mathrm{N}$ stretching mode of the azobenzene group, ${ }^{51,52}$ are good choices. In addition, the well isolated $\mathrm{C} \equiv \mathrm{N}$ stretching band at $2241 \mathrm{~cm}^{-1}$ was used to validate the azo orientation in $\mathrm{P} 4 \mathrm{VP} / \mathrm{ACN}^{53}$ The significant shift of this band to $2226 \mathrm{~cm}^{-1}$ in $\mathrm{P} 4 \mathrm{VP} / \mathrm{AcN}_{\mathrm{CN}}$ is attributed to the loss of the intermolecular $\mathrm{OH}-\mathrm{CN} \mathrm{H}$-bonding present in the crystal form of pure $\mathrm{AcN}^{54}$ which is replaced by OH-P4VP H-bonding in the complex. Indeed, our DFT calculations for $A_{\mathrm{CN}}$ dimers indicate a $12 \mathrm{~cm}^{-1}$ shift toward lower wavenumbers for the $\mathrm{C} \equiv \mathrm{N}$ stretching band of the free nitrile compared to the H-bonded nitrile, consistent with the experimental observation. The reappearance of a weak $2241 \mathrm{~cm}^{-1}$ band for $F_{A}$ near $100 \%$ is indicative of a small amount of uncomplexed crystallized ACN. This does not exclude that there is also some uncomplexed $\mathrm{A}_{\mathrm{CN}}$ that is non-crystallized (i.e. simply dispersed or solvated throughout the complex matrix, as suggested by the results of Figure 2). No indication of such aggregation at high $F_{A}$ was found in the $\mathrm{P} 4 \mathrm{VP} / \mathrm{A}_{\mathrm{H}}$ system, although it is pointed out that there is no IR band for $\mathrm{A}_{\mathrm{H}}$ that is as sensitive a marker as the $\mathrm{CN}$ stretching band for $\mathrm{ACN}_{\mathrm{CN}}$.

For P4VP, the band at $1068 \mathrm{~cm}^{-1}$, assigned to a deformation of the pyridine ring, ${ }^{46}$ is well isolated from azobenzene bands in the $A_{0}$ spectra of the two complexes. In the $\triangle A$ spectra, it is clearly visible for $\mathrm{P} 4 \mathrm{VP} / \mathrm{A}_{\mathrm{CN}}$ but not for $\mathrm{P} 4 \mathrm{VP} / \mathrm{A}_{\mathrm{H}}$, indicating pyridine orientation only for the former. The $1010 \mathrm{~cm}^{-1}$ band for $\mathrm{H}$-bonded pyridine rings also shows negative dichroism for P4VP/AcN only. It should be added that bands associated with the P4VP main chain do not show clear evidence of orientation in the $\Delta A$ spectra, suggesting that only the pyridine side groups orient under irradiation. This is consistent with the lack of (or very small) orientation of the polymer backbone for other $\mathrm{P} 4 \mathrm{VP} / \mathrm{azo}$ complexes $^{55}$ and for azopolymers with the azobenzene in covalently bonded side chains. ${ }^{41}$

For the selected azobenzene bands, the transition dipole moment of the vibration is parallel to the long axis of the azobenzene moiety, based on DFT calculations, so that $\alpha=0^{\circ}$ when using Eq. 1 to calculate $<P_{2}>$. For the P4VP bands, $\alpha=0^{\circ}$ was also used because calculations indicate that their transition dipole moment lies along the principal (N-C4) axis 
of the pyridine ring. As a consequence, the pyridine groups tend to orient approximately parallel to the H-bonded azobenzene, as represented in Scheme 1 for an idealized case.

Photoinduced Orientation and Thermal Relaxation. Figure 5 displays plots of $\left\langle P_{2}\right\rangle$ vs. time for the above-mentioned bands of $\mathrm{P} 4 \mathrm{VP} / \mathrm{A}_{\mathrm{H}}(100 \%)$ and $\mathrm{P} 4 \mathrm{VP} / \mathrm{AcN}_{\mathrm{CN}}(100 \%)$ during a 1800 -s stage of photo-orientation under irradiation, where $\left\langle P_{2}\right\rangle$ becomes increasingly negative (negative because the orientation is perpendicular to the laser polarization direction), followed by a 1600-s stage of thermal relaxation upon cessation of irradiation, where the orientation decreases. The curves for both stages can be fitted by a biexponential function describing a fast and a slow process (see section D of the Supporting Information) ${ }^{56-59}$ Curvefitting of the photo-orientation kinetics indicates that, for both complexes at all $F_{A}$, the time constant of the fast process is on the order of 15-30 s, while the slow process is more than an order of magnitude slower. The fast orientation process is generally ascribed to angular hole burning (AHB) of the trans isomers and the slow process is associated with their angular redistribution (AR) ${ }^{57,58} \mathrm{AHB}$ is due to the rapid depletion of trans isomers with initial orientation along the laser polarization direction when isomerized to the $c i s$ form, ${ }^{60-62}$ while AR, sometimes called orientational redistribution, ${ }^{63}$ involves progressive reorientation of the long axis of the chromophores perpendicular to the laser polarization direction during repeated trans-cis-trans cycles. ${ }^{60-62,64} \mathrm{AR}$ is made possible by photoinduced rotational diffusion (RD), ${ }^{65-67}$ which is strongly influenced by the lateral azo-azo interactions ${ }^{65}$ as well as internal molecular motions of the chromophore, ${ }^{68}$ such as bond torsion, rotation and bending. ${ }^{69,70}$ In the relaxation process, the fast and slow processes can be associated with the rapid thermal isomerization of the cis isomers back to trans conformation and to the much slower thermal RD of the oriented trans isomers toward the isotropic state, respectively. 


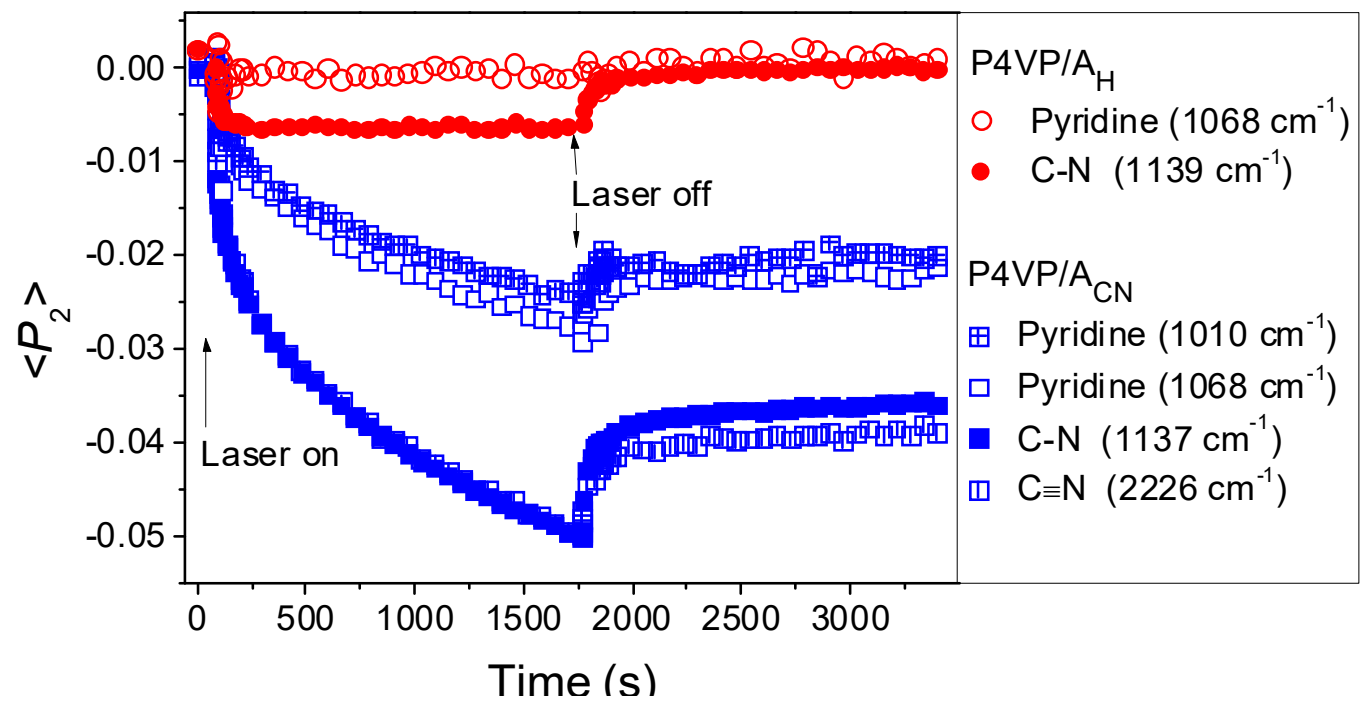

Figure 5. Photoinduced orientation $\left(<P_{2}>\right)$ as a function of time during orientation (laser on) and thermal relaxation (laser off) for different bands of $\mathrm{P} 4 \mathrm{VP} / \mathrm{AcN}_{\mathrm{CN}}(100 \%)$ and $\mathrm{P} 4 \mathrm{VP} / \mathrm{A}_{\mathrm{H}}(100 \%)$.

Figure 5 shows that, for the $\mathrm{P} 4 \mathrm{VP} / \mathrm{A}_{\mathrm{CN}}$ complexes, the photo-orientation and residual orientation (after relaxation) are very similar for the two selected azobenzene bands and for the two selected polymer bands during the whole process. This similarity was observed for all of the P4VP/ACN with different $F_{A}$; therefore, only the bands around $1068 \mathrm{~cm}^{-1}$ for P4VP and $1140 \mathrm{~cm}^{-1}$ for AcN will be shown in the following figures and discussed. Regarding the P4VP bands, it is of interest to mention that their similarity in the complexes with moderate $F_{A}$ (especially around 50\%) indicates that there is no detectable difference in orientation between $\mathrm{H}$-bonded and non $\mathrm{H}$-bonded pyridines (the $1010 \mathrm{~cm}^{-1}$ band being for $\mathrm{H}$-bonded pyridine only, and the $1068 \mathrm{~cm}^{-1}$ band for all pyridine whether $\mathrm{H}$-bonded or not). Possibly, this can be rationalized by there being enough hopping of ACN between pyridine groups during the long irradiation to "homogenize" the pyridine orientation. However, we believe that it is more likely that the orientation of pyridine does not proceed directly through pulling of the pyridine groups via the H-bond (which implies relatively long H-bond lifetimes), but rather by adapting to the reorientation of the azo via AR leaving behind anisotropic free volume. 
For the $100 \%$ complexes, it can be clearly observed in Figure 5 that the azobenzene bands have higher maximum and residual $<P_{2}>$ values than the pyridine bands for both systems, in particular for the $\mathrm{P} 4 \mathrm{VP} / \mathrm{AH}_{\mathrm{H}}(100 \%)$ system where the pyridine rings barely orient. Azobenzene photoisomerization is therefore only partly efficient in reorienting the pyridine rings, in addition to appearing incapable of inducing main-chain orientation as mentioned above. This is in line with the sharp difference in their ability to generate photoinduced birefringence upon illumination. ${ }^{25}$ The difference is also observed in the shape of the photoorientation and relaxation curves, where the relative importance of the fast and slow processes depends on the specific system and on the azo content. ${ }^{56-59}$ For high $F_{A}$, such as shown in Figure 5, the orientation of $\mathrm{A}_{H}$ is dominated by the fast AHB process, leading to a quasi-plateau at long irradiation times. In contrast, the slow AR process is dominant for ACN and no sign of saturation of the orientation can be observed during the 1800-s period of irradiation. More quantitatively, curve fitting to a biexponential function indicates that the slow AR process is responsible for approx. $65 \%$ of the orientation reached at $1800 \mathrm{~s}$ by $\mathrm{ACN}_{\mathrm{CN}}$ but for less than $10 \%$ by $\mathrm{A}_{\mathrm{H}}$ (see Figure S7 in section D of the Supporting Information). It should be noted that the intensity of the orienting light was significantly lower here than in ref. 25, thus making the AR process slower, but the relative differences between the two material systems should not be affected.

The influence of the degree of complexation on orientation is depicted in Figure 6, which plots the maximum $\left\langle P_{2}\right\rangle$ values, $\left\langle P_{2}\right\rangle_{\max }$, measured for the azo and pyridine components after $1800 \mathrm{~s}$ of irradiation, as well as their residual orientation, $\left\langle P_{2}\right\rangle_{\text {res, }}$ expressed as the percentage of the residual $\left\langle P_{2}\right\rangle$ after $1600 \mathrm{~s}$ of thermal relaxation relative to $\left\langle P_{2}\right\rangle_{\max }$, as a function of $F_{A}$. For $\mathrm{A}_{\mathrm{H}}$ (Figure 6a), $\left\langle P_{2}>_{\max }\right.$ decreases exponentially with increasing $F_{A}$ and tends toward a value of 0 , indicating very little or no photoinduced orientation when $F_{A}$ becomes high. The orientation of $\mathrm{ACN}$ also decreases with increasing $F_{A}$, but much more gradually and with greater scatter. Interestingly, $\left\langle P_{2}\right\rangle_{\max }$ for the azobenzene is similar for both complexes when $F_{A}$ is below $4 \%$, that is when the azobenzene molecules are well isolated from one another according to their UV-vis spectra and both materials are amorphous, whereas it is about 4 times higher for $A_{C N}$ than for $A_{H}$ when $F_{A}$ is above $35 \%$, i.e. when liquid 
crystallinity is observed for $\mathrm{P} 4 \mathrm{VP} / \mathrm{ACN}^{25}$ This is also consistent with their similar $\mathrm{AR}$ fractions at low $F_{A}$ and very different $\mathrm{AR}$ fractions at high $F_{A}$ (Figure $\mathrm{S} 7 \mathrm{a}$ ).
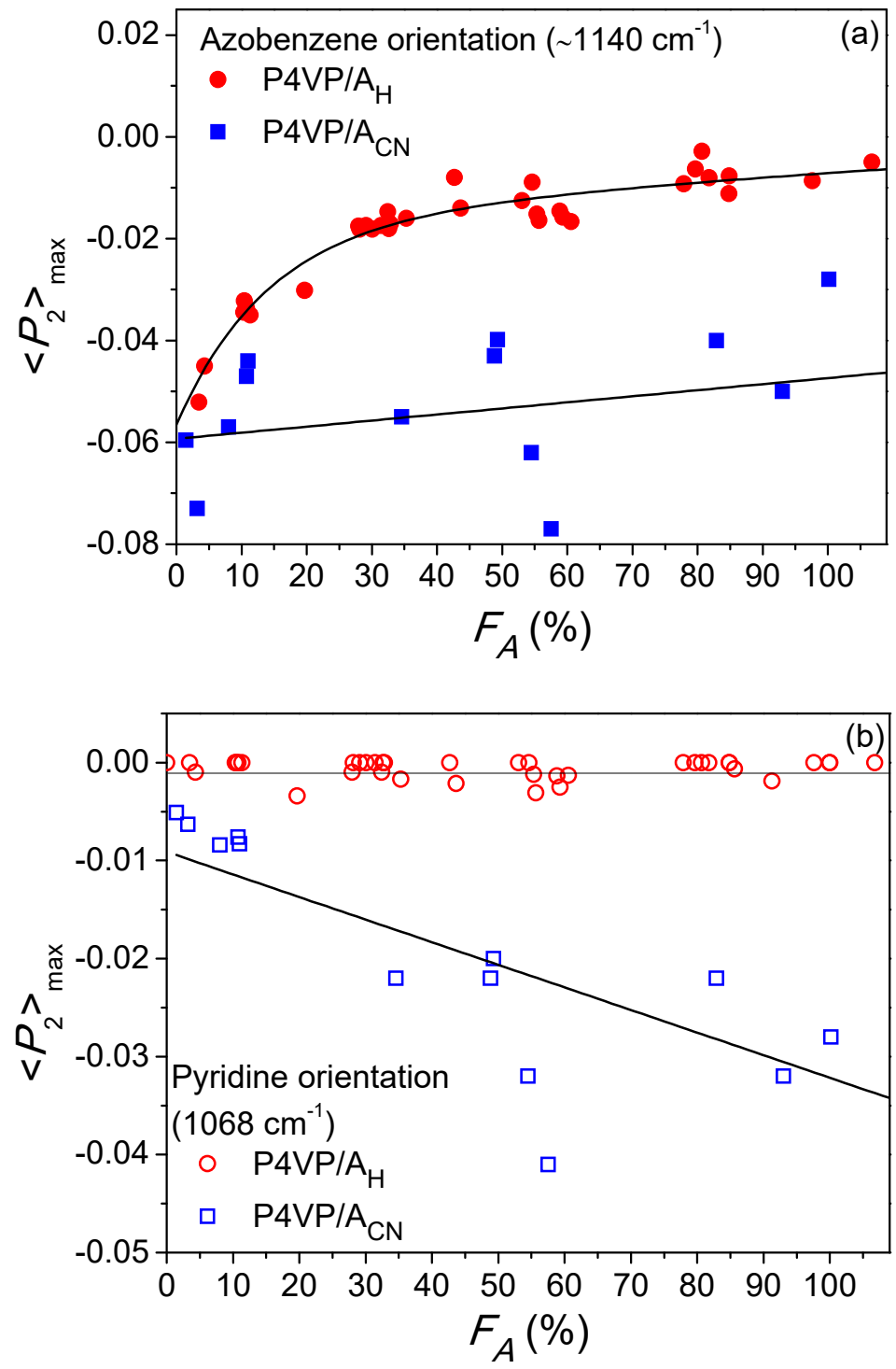


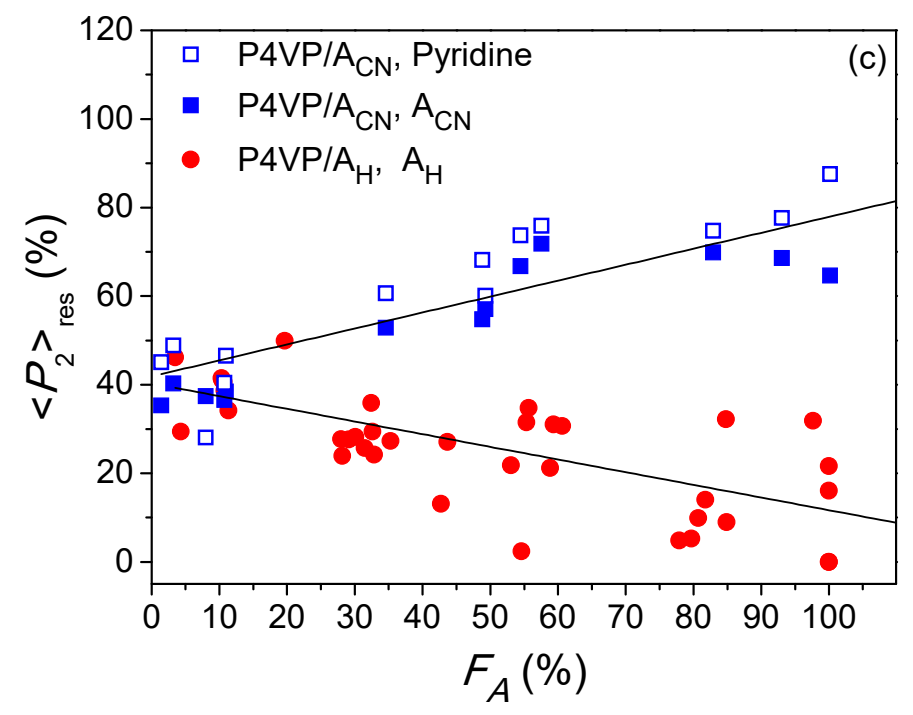

Figure 6. Maximum $<P_{2}>$ as a function of $F_{A}$ for (a) the azobenzene group and (b) the P4VP pyridine rings in the $\mathrm{P} 4 \mathrm{VP} / \mathrm{A}_{\mathrm{CN}}$ and $\mathrm{P} 4 \mathrm{VP} / \mathrm{A}_{\mathrm{H}}$ complexes after $1800 \mathrm{~s}$ of irradiation and (c) the residual orientation as a function of $F_{A}$ for $\mathrm{A}_{\mathrm{CN}}$ and $\mathrm{P} 4 \mathrm{VP}$ in the $\mathrm{P} 4 \mathrm{VP} / \mathrm{A}_{\mathrm{CN}}$ complex and for $\mathrm{A}_{\mathrm{H}}$ in the $\mathrm{P} 4 \mathrm{VP} / \mathrm{A}_{\mathrm{H}}$ complex. The residual orientation, $\left\langle P_{2}\right\rangle_{\text {res, }}$, is expressed as the percentage of the residual $\left\langle P_{2}\right\rangle$ after $1600 \mathrm{~s}$ of thermal relaxation relative to $\left\langle P_{2}\right\rangle_{\text {max }}$. The solid lines represent least-square fits of the data.

For pyridine (Figure $6 \mathrm{~b}$ ), $\left\langle P_{2}\right\rangle_{\max }$ in $\mathrm{P} 4 \mathrm{VP} / \mathrm{ACN}_{\mathrm{C}}$ increases roughly linearly with $F_{A}$, contrasting with the decreasing trend observed for ACN in this complex. This implies that, although the orientation per azo unit decreases with increasing $F_{A}$, their cumulative effect on the polymer increases with $\mathrm{ACN}_{\mathrm{CN}}$ content. On the other hand, for $\mathrm{P} 4 \mathrm{VP} / \mathrm{A}_{\mathrm{H}}$, the $\left\langle P_{2}\right\rangle_{\max }$ measured for P4VP is essentially zero for all $F_{A}$, showing the inability of $\mathrm{A}_{\mathrm{H}}$ to orient the photopassive polymer even at the highest complexation degree.

The difference in the photo-response of $A_{C N}$ and $A_{H}$ is also clear in their residual orientation, $\left\langle P_{2}>_{\text {res, }}\right.$, as a function of $F_{A}$ (Figure 6c). The $\left\langle P_{2}>_{\text {res }}\right.$ of ACN follows the same trend as that of pyridine in $\mathrm{P} 4 \mathrm{VP} / \mathrm{A}_{\mathrm{CN}}$, increasing from about $40 \%$ to about $80 \%$ with increasing $F_{A}$. In contrast, the $\left\langle P_{2}\right\rangle_{\text {res }}$ of $A_{H}$ shows the opposite trend, with the highest value (40\%) at very low $F_{A}$ and the lowest (close to $0 \%$ ) when $F_{A}$ is $100 \%$. The residual orientation 
of the pyridine rings in $\mathrm{P} 4 \mathrm{VP} / \mathrm{A}_{\mathrm{H}}$ is meaningless since they barely orient (Figure $6 \mathrm{~b}$ ). Furthermore, like for $\left\langle P_{2}\right\rangle_{\max }$ (Figure 6a), the $\left\langle P_{2}>_{\text {res }}\right.$ values are very similar for $A_{C N}$ and $A_{H}$ at low $F_{A}$. The kinetics of their photo-orientation and relaxation are also very similar for low $F_{A}$, both in terms of time constants and relative amplitudes of the fast AHB and slow AR processes (Figure S7). In addition, the capacity of $\mathrm{ACN}_{\mathrm{CN}}$ and $\mathrm{A}_{\mathrm{H}}$ to orient the pyridine rings (Figure 6b) tends toward the same value, near zero, when $F_{A}$ is very low. These various observations indicate that the photoresponse of the two complexes is very similar when the chromophores are well isolated but diverges with increasing degree of complexation as intermolecular interactions among the azo molecules, which are much stronger for AcN (with consequent liquid crystallinity), develop.

Comparison with Photoinduced Birefringence. Because infrared analysis provides detailed information on the photoresponse of different components in the system, as opposed to only the average orientation of the system as a whole for birefringence, the results of Figure 6 help understand the saturated PIB results in Figure 3a of Vapaavuori et al. ${ }^{25}$ As mentioned in the Introduction, the birefringence values, when normalized per azo molecule, were found to more than double with increasing $F_{A}$ for $\mathrm{P} 4 \mathrm{VP} / \mathrm{A}_{\mathrm{CN}}$ but to decrease by more than a factor of 2 for $\mathrm{P} 4 \mathrm{VP} / \mathrm{A}_{\mathrm{H}}$. For P4VP/AH, IR shows no measurable pyridine orientation (Figure 6b), indicating that PIB originates only from the photo-orientation of $\mathrm{A}_{\mathrm{H}}$, which is indeed shown in Figure 6 a to decrease gradually with increasing $F_{A}$. In contrast, the increasing PIB per azo for $\mathrm{P} 4 \mathrm{VP} / \mathrm{ACN}_{\mathrm{CN}}$ is the result of two opposing factors when increasing $F_{A}$ : a decrease in ACN orientation (Figure 6a) and an increase in pyridine orientation (Figure 6b). It can thus be concluded that the enhanced birefringence per azo for $\mathrm{P} 4 \mathrm{VP} / \mathrm{A}_{\mathrm{CN}}$ in ref. 25 is in fact due to the P4VP pyridine orientation and not due to higher orientation of the azo molecules themselves. To complement the data given in Figure $3 \mathrm{a}$ of ref. 25, the corresponding absolute birefringence values, not normalized per azo, are shown in Figure S8a (section $\mathrm{E}$ in the Supporting Information), where it can be observed that they increase with increasing $F_{A}$ for both complexes due to the increasing number density of azo molecules in the samples, but much more for the $\mathrm{P} 4 \mathrm{VP} / \mathrm{A}_{\mathrm{CN}}$ complex. This is again consistent with Figure $6 \mathrm{a}$ and $6 \mathrm{~b}$, where 
$A_{C N}$ orients much more than $A_{H}$, in addition to the important fact that only $A_{C N}$ leads to pyridine orientation.

In addition, it is of interest to compare the residual birefringence data, not included in ref. 25 but presented in Figure S8b, with the $\left\langle P_{2}>_{\text {res }}\right.$ measured by IR in Figure 6c. For both complexes and using both techniques, the values are $40-50 \%$ at low $F_{A}$. The residual birefringence values then increase for $\mathrm{P} 4 \mathrm{VP} / \mathrm{A}_{\mathrm{CN}}$ and decrease for $\mathrm{P} 4 \mathrm{VP} / \mathrm{A}_{\mathrm{H}}$ with increasing $F_{A}$. These contrasting trends are consistent with the PM-IRSAS results in Figure $6 \mathrm{c}$, in that the residual photo-orientation of $\mathrm{A}_{\mathrm{CN}}$ and pyridine both increase with increasing $F_{A}$ and contribute to the residual birefringence of $\mathrm{P} 4 \mathrm{VP} / \mathrm{A}_{\mathrm{CN}}$, whereas only the decreasing $\left\langle P_{2}>_{\text {res }}\right.$ of $\mathrm{A}_{\mathrm{H}}$ determines the residual birefringence of $\mathrm{P} 4 \mathrm{VP} / \mathrm{A}_{\mathrm{H}}$.

Kinetics Revealed by the Polarized Absorbances and Implications. As mentioned earlier (Figure 5 and Figure S7), the photoinduced orientation and the thermal relaxation curves of both complexes show the typical biexponential kinetics indicative of a fast and a slow process, where the relative importance of the processes depends on the azo content and the nature of the azo chromophore. ${ }^{56-59}$ To explore this aspect in greater depth, we turn to the unique advantage of PM-IRSAS of simultaneously recording spectra in the two orthogonal polarizations in addition to the $\left\langle P_{2}\right\rangle$ values. Figure 7 shows the evolution of the normalized absorbance of the trans azobenzene band at $1140 \mathrm{~cm}^{-1}$ for the IR beam polarized parallel $\left(A_{p}\right)$ and perpendicular $\left(A_{s}\right)$ to the laser polarization during photo-orientation and thermal relaxation. We will focus first on the photo-orientation kinetics. For both complexes, $A_{p}$ and $A_{s}$ drop steeply at the earliest stage of illumination, indicating a rapid depletion of the trans isomer with a characteristic time on the order of 7-15 s, which is consistent with the time constant of the fast process obtained by fitting the photo-orientation curves in Figure 5 . The decrease is more pronounced for $A_{p}$ than for $A_{s}$ (their difference being directly proportional to the $\left\langle P_{2}\right\rangle$ values). This provides additional support to the assignment of the fast photoorientation process to angular hole burning, since the probability of light absorption by trans isomers and their conversion to cis isomers depends on the cosine squared of the angle between the laser polarization direction and the electronic transition dipole moment of the azobenzene molecule, and thus there is a greater decrease in the absorption direction parallel 
to the incident linearly polarized illumination. The concomitant formation of cis conformers is confirmed in Figures S9 and S10 (section F in the Supporting Information), which show a simultaneous increase in $A_{p}$ and $A_{s}$ for the band at $1505 \mathrm{~cm}^{-1}$, associated with both cis and trans isomers but with a higher absorption coefficient for the cis isomer and an initial increase that is larger for $A_{s}$ than for $A_{p}$. Significantly, for both complexes, the abrupt initial change of $A_{p}$ and $A_{s}$ and the generated difference between $A_{p}$ and $A_{s}$ is much smaller when $F_{A}$ is $80 \%$ than when $F_{A}$ is $10 \%$. This indicates that the efficiency of the AHB process is hindered by azobenzene intermolecular interactions and by increased steric hindrance at high $F_{A}$. It is also consistent with the UV-vis results of Figure S6 showing that the percentage of trans isomers under irradiation is higher for both complexes at high $F_{A}$ than at low $F_{A}$.
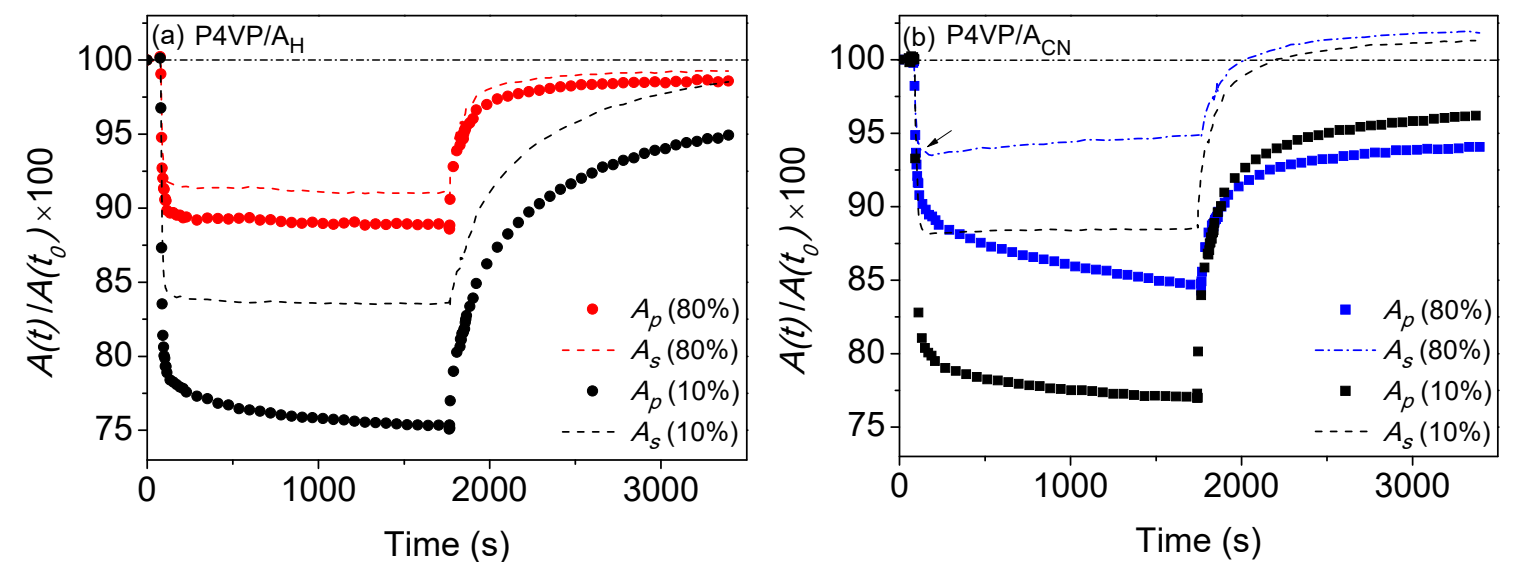

Figure 7. Evolution of the IR absorbance of the trans azobenzene band near $1140 \mathrm{~cm}^{-1}$ polarized parallel $\left(A_{p}\right)$ and perpendicular $\left(A_{s}\right)$ to the polarization direction of the laser as a function of time during photo-orientation and thermal relaxation for (a) $\mathrm{P} 4 \mathrm{VP} / \mathrm{A}_{\mathrm{H}}$ and (b) $\mathrm{P} 4 \mathrm{VP} / \mathrm{ACN}_{\mathrm{CN}}$ complexes with $F_{A}$ of $10 \%$ and $80 \%$. The values are expressed as the percentage of the real-time absorbance, $A(t)$, relative to the absorbance before irradiation, $A\left(t_{0}\right)$.

For longer irradiation times, the azobenzene photoresponse shows a strong dependence on both the composition and the nature of the chromophores. For $\mathrm{P} 4 \mathrm{VP} / \mathrm{A}_{\mathrm{H}}(80 \%)$, the $\mathrm{AH}_{\mathrm{H}} A_{p}$ and $A s$ become quasi-plateaus with similar slopes, with the consequence that the photoorientation also rapidly reaches a plateau (Figure 5). This confirms the dominance of AHB 
over the AR process (see also Figure S7a). For P4VP/Aн(10\%), $A_{s}$ also forms a quasi-plateau but $A_{p}$ continues to decrease for irradiation times well beyond the time constant of the AHB process, indicative of a minor contribution from the slow process. The impact and origin of the slow AR process are more explicit for the P4VP/AcN complex (Figure 7b), for which not only does the $A_{p}$ continue to decrease after the initial AHB but the $A_{s}$ actually rises after $\sim 80$ $\mathrm{s}$ of illumination (indicated by an arrow), implying a reorientation of trans isomers away from the laser polarization direction (p) and along the perpendicular direction (s). It is for this reason that the photo-orientation of $\mathrm{A}_{\mathrm{CN}}$ (proportional to the difference between $A_{p}$ and $A_{s}$ ) continues to grow at a slow rate and never saturates over the timescale of the experiment (Figure 5). An increase in $A_{s}$ after the rapid AHB was also reported using UV-vis spectroscopy for cyano-tailed azobenzenes covalently bonded as side chains to polyurethane, ${ }^{71}$ and for 1-naphthyl-azomethoxybenzene in glassy $o$-terphenyl. ${ }^{72}$ The fact that $A_{s}$ increases under irradiation after the rapid initial AHB supports the conclusion that the slow process of photo-orientation is due to the AR of the trans conformers towards the direction perpendicular to the laser polarization and is not due to AHB or to photobleaching. It can also be observed from Figure $7 \mathrm{~b}$ (and Figure S7a for additional $F_{A}$ ) that the relative importance of the fast $\mathrm{AHB}$ and slow $\mathrm{AR}$ processes depends on the degree of complexation of $\mathrm{P} 4 \mathrm{VP} / \mathrm{A}_{\mathrm{CN}}$, with AR contributing more strongly at high $F_{A}$.

We now turn to the thermal relaxation kinetics shown in Figure 7 for 10 and $80 \%$ azo content (and Figure S7b for additional $F_{A}$ ), again in terms of a fast and a slow process. For $\mathrm{P} 4 \mathrm{VP} / \mathrm{A}_{\mathrm{H}}, A_{s}$ and $A_{p}$ recover almost fully to pre-irradiation absorbance values, notably about $99 \%$ at all $F_{A}$ for $A_{s}$ and increasing linearly from $95 \%$ to $99 \%$ with $F_{A}$ for $A_{p}$. This agrees with the earlier conclusion that $\mathrm{AHB}$ is the main contributor to the photo-orientation of $\mathrm{P} 4 \mathrm{VP} / \mathrm{A}_{\mathrm{H}}$, especially at high $F_{A}$, which is then efficiently erased by the reverse process of cis-trans thermal isomerization once irradiation ceases. The trend in Figure $6 \mathrm{c}$ showing the highest residual orientation (near $40 \%$ ) of $\mathrm{A}_{\mathrm{H}}$ at low $F_{A}$ is explained by the additional contribution of $\mathrm{AR}$ to $\left\langle P_{2}\right\rangle_{\max }$, which reverts to isotropic orientation by rotational diffusion much more slowly than cis-trans isomerization during relaxation, as illustrated in Figure 7a for $\mathrm{P} 4 \mathrm{VP} / \mathrm{A}_{\mathrm{H}}(10 \%)$. For the $\mathrm{P} 4 \mathrm{VP} / \mathrm{A}_{\mathrm{CN}}$ complex, Figure $7 \mathrm{~b}$ shows that $A_{s}$ even reaches values 
above the pre-irradiation value at the longer relaxation times, which is explained by the reorientation of $A_{C N}$ perpendicular to the laser polarization due to the AR process during irradiation.

Final Discussion. To summarize, the results regarding the fast and slow processes during irradiation indicate that 1) the (fast) AHB process is most efficient at low azo content for both complexes, where the azo chromophores are well isolated from one another, and decreases in efficiency with increasing $F_{A}$, and 2) the capacity of $A_{H}$ and $A_{C N}$ to undergo AR is identical at the lowest $F_{A}$, whereas it increases with $F_{A}$ for $A_{C N}$ and decreases with $F_{A}$ for $\mathrm{A}_{\mathrm{H}}$. The almost identical cis content under irradiation observed for both complexes throughout the complexation range studied indicates that the difference in azo-azo interaction strength does not significantly alter the trans-cis-trans isomerization cycles. On the other hand, the AR process is enhanced by stronger azo-azo interactions in $\mathrm{P} 4 \mathrm{VP} / \mathrm{AcN}_{\mathrm{CN}}$, in line with the observation for copolymers containing randomly distributed azo (4-nitroazobenzene) and non-azo (4-nitrophenyl benzoate) side-chains with a high dipole moment where the lightinduced orientation of the azo groups induces orientation of the photopassive side-chains via a cooperative effect. ${ }^{73,74}$ Analogously, cooperative motion resulting from the interplay of $\mathrm{H}-$ bonding and lateral $\pi-\pi$ interactions was reported to enhance the saturated and remnant values of birefringence in an $\mathrm{H}$-bonded bisazopolymer with high $\mathrm{ACN}_{\mathrm{CN}}$ fraction. ${ }^{75}$ For $\mathrm{P} 4 \mathrm{VP} / \mathrm{A}_{\mathrm{H}}$, as opposed to $\mathrm{P} 4 \mathrm{VP} / \mathrm{A}_{\mathrm{CN}}$, the intermolecular interactions appear to be too weak to drive the AR process and azo orientation decreases with increasing $F_{A}$ due to higher steric hindrance. The difference in relative contributions of the two mechanisms thus explains why the photoorientation of both complexes is essentially identical at low $F_{A}$, where the azo units are well isolated from one another and the material is amorphous, but is different at higher $F_{A}$, where azo-azo interactions occur and $\mathrm{P} 4 \mathrm{VP} / \mathrm{A}_{\mathrm{CN}}$ is liquid crystalline, as indicated by the significant blue shift in the visible spectrum of $\mathrm{P} 4 \mathrm{VP} / \mathrm{A}_{\mathrm{CN}}$ and the appearance of birefringence in polarized optical microscopy with increasing $F_{A}$. These findings support the material design guideline that strong azo-azo interactions are beneficial for photo-orientation and its temporal stability, and that $\mathrm{AcN}_{\mathrm{CN}}$, having a rod-like shape and intermediate dipole moment, is an ideal 
mesogen for supramolecular complexation in that it allows formation of a liquid crystalline mesophase without promoting disruptive phase separation even at high $F_{A}$.

In a previous paper, we have shown that the orientation of the P4VP pyridine groups increases with azo content in amorphous hydrogen- and halogen-bonded P4VP/azo complexes. ${ }^{55}$ The results of the present study provide a clearer picture by showing that pyridine orientation only occurs in response to the AR process. When the AHB process dominates, as is the case for $\mathrm{P} 4 \mathrm{VP} / \mathrm{A}_{\mathrm{H}}$, there is no pyridine orientation even at high $F_{A}$. This suggests that the pyridine groups orient by adaptation and cooperative motion induced by the AR of the azo groups. This process is favored by the free volume generated around the azo by the effect of "localized photoplasticization". ${ }^{76}$ The residual orientation in Figure 6c is almost identical for ACN and the pyridine groups in a given complex, supporting the proposed cooperative orientation mechanism and suggesting that the thermal relaxation by rotational diffusion is also cooperative. Additionally, these residual orientations are roughly proportional to the relative importance of the AR process as determined from the biexponential fits of the photo-orientation curves. While this is certainly not the only element at play, it is consistent with the importance of azo-azo interactions in increasing orientation of both the azo and polymer host and in enabling photomechanical effects. Further validation of the proposed model could be obtained by conducting photo-orientation studies for a given $F_{A}$ at variable temperatures, or at variable distances from $T_{g}$ as previously done with azocontaining molecular glasses, ${ }^{77}$ where the rate constants of the AHB and AR processes would be expected to evolve differently.

\section{CONCLUSIONS}

In this contribution, we used polarization modulation infrared structural absorbance spectroscopy (PM-IRSAS) to investigate the unusually large influence of the tail group of azobenzene, notably cyano $\left(\mathrm{ACN}_{\mathrm{C}}\right)$ vs. hydrogen $\left(\mathrm{A}_{\mathrm{H}}\right)$, on the photoresponse of their hydrogenbonded complexes with poly(4-vinylpyridine) (P4VP). Linearly polarized irradiation of $\mathrm{P} 4 \mathrm{VP} / \mathrm{A}_{\mathrm{CN}}$ produces higher and more temporally stable photo-orientation than $\mathrm{P} 4 \mathrm{VP} / \mathrm{A}_{\mathrm{H}}$ in spite of their similar cis conformer content under illumination. Orientation of the 
photopassive pyridine rings occurs for $\mathrm{P} 4 \mathrm{VP} / \mathrm{A}_{\mathrm{CN}}$ complexes only, in spite of the similar extent and strength of the hydrogen-bonding interaction, and increases with AcN content, in contrast to the behavior of the photoactive azo whose orientation decreases with increasing azo content for both complexes.

Curve fitting of the photo-orientation curves and investigation of the photoresponse of azobenzene with $p$ and $s$ polarized IR indicate very different relative contributions from the angular hole burning (AHB) and angular redistribution (AR) mechanisms. For P4VP/ $\mathrm{A}_{H}$, the photo-orientation is mainly limited to AHB, the efficiency of which is reduced at high azo content and does not allow for stable orientation or transfer of azobenzene orientation to $\mathrm{P} 4 \mathrm{VP}$ pyridine orientation though the hydrogen bond. For P4VP/ACN, there is an increasing contribution of the AR process to the photo-orientation with increasing azo content linked to the emergence of a liquid crystalline mesophase at higher AcN content due to its much higher dipole moment compared to Aн. These results demonstrate, for the first time, that the beneficial effect of chromophore-chromophore interactions on photo-orientation stems from their promoting the AR photo-orientation mechanism. In addition, efficient AR is observed to be a prerequisite for efficient orientation of the photopassive polymer. Overall, this molecular-level understanding of photo-orientation processes is important for optimizing photoresponsive materials as well as the conditions for optimal orientation transfer from photoactive to photopassive molecules.

\section{ASSOCIATED CONTENT}

\section{Supporting Information}

The Supporting Information is available free of charge on the ACS Publications website at DOI: Details about the determination of the azobenzene content and extent of hydrogen bonding in supramolecular complexes; Additional UV-vis spectroscopy, photoinduced birefringence, and infrared spectroscopy results. 
AUTHOR INFORMATION

Corresponding Author

* c.pellerin@umontreal.ca

\section{Author Contributions}

The manuscript was written through contributions of all authors. All authors have given approval to the final version of the manuscript.

\section{ACKNOWLEDGMENTS}

This work was supported by the Natural Science and Engineering Research Council of Canada (NSERC) and Fonds de Recherche du Québec - Nature et Technologies (FRQNT). X.W. thanks the China Scholarship Council (CSC) and Université de Montréal and J.V. the FRQNT and Banting postdoctoral fellowships for generous financial support.

\section{REFERENCES}

(1) Natansohn, A.; Rochon, P. Photoinduced Motions in Azo-containing Polymers. Chem. Rev. 2002, 102, 4139-4175.

(2) Bandara, H. M.; Burdette, S. C. Photoisomerization in Different Classes of Azobenzene. Chem. Soc. Rev. 2012, 41, 1809-1825.

(3) O'Neill, M.; Kelly, S. M. Photoinduced Surface Alignment for Liquid Crystal Displays. J. Phys. D 2000, 33, R67-R84.

(4) Paterson, J.; Natansohn, A.; Rochon, P.; Callender, C. L.; Robitaille, L. Optically Inscribed Surface Relief Diffraction Gratings on Azobenzene-containing Polymers for Coupling Light into Slab Waveguides. Appl. Phys. Lett. 1996, 69, 3318-3320. 
(5) Bang, C.-U.; Shishido, A.; Ikeda, T. Azobenzene Liquid-Crystalline Polymer for Optical Switching of Grating Waveguide Couplers with a Flat Surface. Macromol. Rapid Commun. 2007, 28, 1040-1044.

(6) Shishido, A. Rewritable Holograms Based on Azobenzene-Containing LiquidCrystalline Polymers. Polym. J. 2010, 42, 525-533.

(7) Hvilsted, S.; Sánchez, C.; Alcalá, R. The Volume Holographic Optical Storage Potential in Azobenzene Containing Polymers. J. Mater. Chem. 2009, 19, 6641-6648.

(8) Yu, H.; Liu, H.; Kobayashi, T. Fabrication and Photoresponse of Supramolecular Liquid-Crystalline Microparticles. ACS Appl. Mater. Interfaces 2011, 3, 1333-1340.

(9) Ube, T.; Ikeda, T. Photomobile Polymer Materials with Crosslinked Liquid-Crystalline Structures: Molecular Design, Fabrication, and Functions. Angew. Chem. Int. Ed. 2014, 53, 10290-10299.

(10) Takashima, Y.; Hatanaka, S.; Otsubo, M.; Nakahata, M.; Kakuta, T.; Hashidzume, A.; Yamaguchi, H.; Harada, A. Expansion-Contraction of Photoresponsive Artificial Muscle Regulated by Host-Guest Interactions. Nat. Commun. 2012, 3, 1270.

(11) Yamada, M.; Kondo, M.; Mamiya, J.; Yu, Y.; Kinoshita, M.; Barrett, C. J.; Ikeda, T. Photomobile Polymer Materials: Towards Light-Driven Plastic Motors. Angew. Chem. Int. Ed. 2008, 47, 4986-4988.

(12) Xue, X.; Zhu, J.; Zhang, Z.; Zhou, N.; Tu, Y.; Zhu, X. Soluble Main-Chain Azobenzene Polymers via Thermal 1,3-Dipolar Cycloaddition: Preparation and Photoresponsive Behavior. Macromolecules 2010, 43, 2704-2712. 
(13) Fang, L.; Zhang, H.; Li, Z.; Zhang, Y.; Zhang, Y.; Zhang, H. Synthesis of Reactive Azobenzene Main-Chain Liquid Crystalline Polymers via Michael Addition Polymerization and Photomechanical Effects of Their Supramolecular HydrogenBonded Fibers. Macromolecules 2013, 46, 7650-7660.

(14) Kulikovska, O.; Goldenberg, L. M.; Stumpe, J. Supramolecular Azobenzene-Based Materials for Optical Generation of Microstructures. Chem. Mater. 2007, 19, 33433348.

(15) Ahmed, R.; Priimagi, A.; Faul, C. F.; Manners, I. Redox-Active, Organometallic Surface-Relief Gratings from Azobenzene-Containing Polyferrocenylsilane Block Copolymers. Adv. Mater. 2012, 24, 926-931.

(16) Vapaavuori, J.; Goulet-Hanssens, A.; Heikkinen, I. T. S.; Barrett, C. J.; Priimagi, A. Are Two Azo Groups Better than One? Investigating the Photoresponse of PolymerBisazobenzene Complexes. Chem. Mater. 2014, 26, 5089-5096.

(17) Wang, X.; Vapaavuori, J.; Wang, X.; Sabat, R. G.; Pellerin, C.; Bazuin, C. G. Influence of Supramolecular Interaction Type on Photoresponsive Azopolymer Complexes: A Surface Relief Grating Formation Study. Macromolecules 2016, 49, 4923-4934.

(18) Zhang, Q.; Wang, X.; Barrett, C. J.; Bazuin, C. G. Spacer-Free Ionic Dye-Polyelectrolyte Complexes: Influence of Molecular Structure on Liquid Crystal Order and Photoinduced Motion. Chem. Mater. 2009, 21, 3216-3227.

(19) Zhang, Q.; Bazuin, C. G.; Barrett, C. J. Simple Spacer-Free Dye-Polyelectrolyte Ionic Complex: Side-Chain Liquid Crystal Order with High and Stable Photoinduced Birefringence. Chem. Mater. 2008, 20, 29-31. 
(20) Koskela, J. E.; Vapaavuori, J.; Ras, R. H. A.; Priimagi, A. Light-Driven Surface Patterning of Supramolecular Polymers with Extremely Low Concentration of Photoactive Molecules. ACS Macro Lett. 2014, 3, 1196-1200.

(21) Gao, J.; He, Y.; Liu, F.; Zhang, X.; Wang, Z.; Wang, X. Azobenzene-Containing Supramolecular Side-Chain Polymer Films for Laser-Induced Surface Relief Gratings. Chem. Mater. 2007, 19, 3877-3881.

(22) Priimagi, A.; Lindfors, K.; Kaivola, M.; Rochon, P. Efficient Surface-Relief Gratings in Hydrogen-Bonded Polymer-Azobenzene Complexes. ACS Appl. Mater. Interfaces 2009, $1,1183-1189$.

(23) Priimagi, A.; Kaivola, M.; Rodriguez, F. J.; Kauranen, M. Enhanced Photoinduced Birefringence in Polymer-Dye Complexes: Hydrogen Bonding Makes a Difference. Appl. Phys. Lett. 2007, 90, 121103.

(24) Priimagi, A.; Vapaavuori, J.; Rodriguez, F. J.; Faul, C. F. J.; Heino, M. T.; Ikkala, O.; Kauranen, M.; Kaivola, M. Hydrogen-Bonded Polymer-Azobenzene Complexes: Enhanced Photoinduced Birefringence with High Temporal Stability through Interplay of Intermolecular Interactions. Chem. Mater. 2008, 20, 6358-6363.

(25) Vapaavuori, J.; Valtavirta, V.; Alasaarela, T.; Mamiya, J.-I.; Priimagi, A.; Shishido, A.; Kaivola, M. Efficient Surface Structuring and Photoalignment of Supramolecular Polymer-Azobenzene Complexes through Rational Chromophore Design. J. Mater. Chem. 2011, 21, 15437-15441. 
(26) Vapaavuori, J.; Priimagi, A.; Kaivola, M. Photoinduced Surface-Relief Gratings in Films of Supramolecular Polymer-Bisazobenzene Complexes. J. Mater. Chem. 2010, 20, 5260-5264.

(27) Priimagi, A.; Cavallo, G.; Forni, A.; Gorynsztejn-Leben, M.; Kaivola, M.; Metrangolo, P.; Milani, R.; Shishido, A.; Pilati, T.; Resnati, G.; Terraneo, G. Halogen Bonding versus Hydrogen Bonding in Driving Self-Assembly and Performance of LightResponsive Supramolecular Polymers. Adv. Funct. Mater. 2012, 22, 2572-2579.

(28) Priimagi, A.; Cavallo, G.; Metrangolo, P.; Resnati, G. The Halogen Bond in the Design of Functional Supramolecular Materials: Recent Advances. Acc. Chem. Res. 2013, 46, 2686-2695.

(29) Saccone, M.; Dichiarante, V.; Forni, A.; Goulet-Hanssens, A.; Cavallo, G.; Vapaavuori, J.; Terraneo, G.; Barrett, C. J.; Resnati, G.; Metrangolo, P.; Priimagi, A. Supramolecular Hierarchy among Halogen and Hydrogen Bond Donors in LightInduced Surface Patterning. J. Mater. Chem. C 2015, 3, 759-768.

(30) Priimagi, A.; Shevchenko, A.; Kaivola, M.; Rodriguez, F. J.; Kauranen, M.; Rochon, P. High and Stable Photoinduced Anisotropy in Guest-Host Polymer Mediated by Chromophore Aggregation. Opt. Lett. 2010, 35, 1813-1815.

(31) Tawa, K.; Kamada, K.; Kiyohara, K.; Ohta, K.; Yasumatsu, D.; Sekkat, Z.; Kawata, S. Photoinduced Reorientation of Azo Dyes Bonded to Polyurethane Studied by Polarized FT-IR Spectroscopy. Macromolecules 2001, 34, 8232-8238. 
(32) Tawa, K.; Zettsu, N.; Minematsu, K.; Ohta, K.; Namba, A.; Tran-Cong, Q. Photoinduced Reorientation of Azo-Dyes Covalently Linked to a Styrene Copolymer in Bulk State. J. Photochem. Photobiol. A 2001, 143, 31-38.

(33) Zebger, I.; Rutloh, M.; Hoffmann, U.; Stumpe, J.; Siesler, H. W.; Hvilsted, S. Photoorientation of a Liquid Crystalline Polyester with Azobenzene Side Groups. 1. Effects of Irradiation with Linearly Polarized Blue Light. J. Phys. Chem. A 2002, 106, 3454-3462.

(34) Zebger, I.; Kulinna, C.; Siesler, H. W.; Andruzzi, F.; Pedersen, M.; Ramanujam, P. S.; Hvilsted, S. The Influence of Substituents on the Orientational Behaviour of Novel Azobenzene Side-Chain Polyesters. Macromol. Symp. 1995, 94, 159-170.

(35) Han, M.; Kidowaki, M.; Ichimura, K.; Ramanujam, P. S.; Hvilsted, S. Influence of Structures of Polymer Backbones on Cooperative Photoreorientation Behavior of pCyanoazobenzene Side Chains. Macromolecules 2001, 34, 4256-4262.

(36) Hvilsted, S.; Andruzzi, F.; Kulinna, C.; Siesler, H. W.; Ramanujam, P. S. Novel SideChain Liquid Crystalline Polyester Architecture for Reversible Optical Storage. Macromolecules 1995, 28, 2172-2183.

(37) Kulinna, C.; Hvilsted, S.; Hendann, C.; Siesler, H. W.; Ramanujam, P. S. Selectively Deuterated Liquid Crystalline Cyanoazobenzene Side-Chain Polyesters. 3. Investigations of Laser-Induced Segmental Mobility by Fourier Transform Infrared Spectroscopy. Macromolecules 1998, 31, 2141-2151. 
(38) Tawa, K.; Kamada, K.; Ohta, K. Azo-Dye-Structure Dependence of Photoinduced Anisotropy Observed in PMMA Films. J. Photochem. Photobiol. A 2000, 134, 185191.

(39) Tawa, K.; Kamada, K.; Sakaguchi, T.; Ohta, K. Photoinduced Anisotropy in a Polymer Doped with Azo Dyes in the Photostationary State Studied by Polarized FT-IR Spectroscopy. Appl. Spectrosc. 2016, 52, 1536-1540.

(40) Tawa, K.; Kamada, K.; Sakaguchi, T.; Ohta, K. Local Environment Dependence of Photoinduced Anisotropy Observed in Azo-Dye-Doped Polymer Films. Polymer 2000, $41,3235-3242$.

(41) Labarthet, F. L.; Freiberg, S.; Pellerin, C.; Pézolet, M.; Natansohn, A.; Rochon, P. Spectroscopic and Optical Characterization of a Series of Azobenzene-Containing Side-Chain Liquid Crystalline Polymers. Macromolecules 2000, 33, 6815-6823.

(42) Pellerin, C.; Prud'homme, R. E.; Pézolet, M.; Weinstock, B. A.; Griffiths, P. R. Deformation and Relaxation of Polymers Studied by Ultrarapid Scanning FT-IR Spectrometry. Macromolecules 2003, 36, 4838-4843.

(43) Buffeteau, T.; Pézolet, M. In situ Study of Photoinduced Orientation in Azopolymers by Time-Dependent Polarization Modulation Infrared Spectroscopy. Appl. Spectrosc. 2016, 50, 948-955.

(44) Liang, Y.; Mauran, D.; Prud'homme, R. E.; Pellerin, C. A New Method for the Timeresolved Analysis of Structure and Orientation: Polarization Modulation Infrared Structural Absorbance Spectroscopy. Appl. Spectrosc. 2008, 62, 941-947. 
(45) Vapaavuori, J.; Bazuin, C. G.; Pellerin, C. Taming Macromolecules with Light: Lessons Learned from Vibrational Spectroscopy. Macromol. Rapid Commun. 2018, 39, 1700430.

(46) Wang, X.; Bazuin, C. G.; Pellerin, C. Quantitative Analysis of Hydrogen Bonding in Electrospun Fibers of Poly(4-vinyl pyridine)/(4,4'-Biphenol) Complexes by ATR using Liquid Blends as Models. Vib. Spectrosc. 2014, 71, 18-23.

(47) Garton, A. Some Observations on Kinetic and Steric Limitations to Specific Interactions in Miscible Polymer Blends. Polym. Eng. Sci. 1984, 24, 112-116.

(48) Kojima, M.; Nebashi, S.; Ogawa, K.; Kurita, N. Effect of Solvent on Cis-to-Trans Isomerization of 4-Hydroxyazobenzene Aggregated through Intermolecular Hydrogen Bonds. J. Phys. Org. Chem. 2005, 18, 994-1000.

(49) Tang, Z.; Johal, M. S.; Scudder, P.; Caculitan, N.; Magyar, R. J.; Tretiak, S.; Wang, H.-L. Study of the Non-Covalent Interactions in Langmuir-Blodgett Films: An Interplay between $\pi-\pi$ and Dipole-Dipole Interactions. Thin Solid Films 2007, 516, $58-66$.

(50) Gabor, G.; Frei, Y. F.; Fischer, E. Tautomerism and Geometric Isomerism in Arylazophenols and Naphthols. IV. Spectra and Reversible Photoreactions of m- and p-Hydroxyazobenzene. J. Phys. Chem. 1968, 72, 3266-3272.

(51) Minisini, B.; Fayet, G.; Tsobnang, F.; Bardeau, J. F. Density Functional Theory Characterisation of 4-Hydroxyazobenzene. J. Mol. Model. 2007, 13, 1227-1235. 
(52) Tecklenburg, M. M. J.; Kosnak, D. J.; Bhatnagar, A.; Mohanty, D. K. Vibrational Characterization of Azobenzenes, Azoxybenzenes and Azoaromatic and Azoxyaromatic Polyethers. J. Raman Spectrosc. 1997, 28, 755-763.

(53) Getahun, Z.; Huang, C. Y.; Wang, T.; De Leon, B.; DeGrado, W. F.; Gai, F. Using Nitrile-derivatized Amino Acids as Infrared Probes of Local Environment. J. Am. Chem. Soc. 2003, 125, 405-411.

(54) Zhang, C. Z. 4-(4-Hydroxy-phenyl-diazen-yl)-benzonitrile. Acta Crystallogr. E 2008, 64, o618.

(55) Vapaavuori, J.; Heikkinen, I. T. S.; Dichiarante, V.; Resnati, G.; Metrangolo, P.; Sabat, R. G.; Bazuin, C. G.; Priimagi, A.; Pellerin, C. Photomechanical Energy Transfer to Photopassive Polymers through Hydrogen and Halogen Bonds. Macromolecules 2015, $48,7535-7542$.

(56) Brown, D.; Natansohn, A.; Rochon, P. Azo Polymers for Reversible Optical Storage. 5. Orientation and Dipolar Interactions of Azobenzene Side Groups in Copolymers and Blends Containing Methyl Methacrylate Structural Units. Macromolecules 1995, 28 , 6116-6123.

(57) Chien, F. S. S.; Lin, C. Y.; Huang, C. R.; Chang, C. S.; Hsu, C. C. Polar Orientation Induced by Local Photo-assisted Poling in Azo Copolymer Films. J. Opt. Soc. Am. 2010, 27, 773-778.

(58) Chien, F. S. S.; Lin, C. Y.; Hsu, C. C. Local Photo-assisted Poling of Azo Copolymer Films by Scanning Probe Microscopy. J. Phys. D 2008, 41, 235502. 
(59) Ho, M. S.; Natansohn, A.; Rochon, P. Azo Polymers for Reversible Optical Storage. 7. The Effect of the Size of the Photochromic Groups. Macromolecules 1995, 28, 61246127.

(60) Lessard, R. A.; Dumont, M. L.; Sekkat, Z. Dynamical Study of Photoinduced Anisotropy and Orientational Relaxation of Azo Dyes in Polymeric Films: Poling at Room Temperature. Proc. SPIE-Int. Soc. Opt. Eng. 1993, 1774, 188-199.

(61) Blanche, P. A.; Lemaire, P. C.; Dumont, M.; Fischer, M. Photoinduced Orientation of Azo Dye in Various Polymer Matrices. Opt. Lett. 1999, 24, 1349-1351.

(62) Fischer, M.; El Osman, A.; Blanche, P.-A.; Dumont, M. Photoinduce Dichroism as a Tool for Understanding Orientational Mobility of Photoisomerizable Dyes in Amorphous Matrices. Synth. Met. 2000, 115, 139-144.

(63) Sekkat, Z.; Wood, J.; Aust, E. F.; Knoll, W.; Volksen, W.; Miller, R. D. Light-Induced Orientation in a High Glass transition Temperature Polyimide with Polar Azo Dyes in the Side Chain. J. Opt. Soc. Am. 1996, 13, 1713-1724.

(64) Smith, M. A. G.; Mitchell, G. R.; O'Leary, S. V. Local Gratings due to Angular Hole Burning in a Photorefractive Polymer. J. Opt. A: Pure Appl. Opt. 2002, 4, 474-480.

(65) Fuhrmann, T.; Kunze, M.; Wendorff, J. H. "Monte Carlo kinetics" for the Simulation of Photoreactions in Polymers. Macromol. Theory Simul. 1998, 7, 421-429.

(66) Petri, A.; Kummer, S.; Bräuchle, C. Structuring Cholesteric Polysiloxanes by Photoinduced Rotational Diffusion. Liq. Cryst. 1995, 19, 277-287. 
(67) Chigrinov, V.; Pikin, S.; Verevochnikov, A.; Kozenkov, V.; Khazimullin, M.; Ho, J.; Huang, D. D.; Kwok, H. S. Diffusion Model of Photoaligning in Azo-Dye Layers. Phys. Rev. E 2004, 69, 061713.

(68) Van Leuven, P.; Cantatore, V.; Persico, M. Photo-Orientation of Axial Molecules. Phys. Chem. Chem. Phys. 2012, 14, 1957-1964.

(69) Cantatore, V.; Granucci, G.; Persico, M. The Photo-orientation of Azobenzene in Viscous Solutions, Simulated by a Stochastic Model. Phys. Chem. Chem. Phys. 2014, $16,25081-25092$.

(70) Cusati, T.; Granucci, G.; Persico, M. Photodynamics and Time-Resolved Fluorescence of Azobenzene in Solution: a Mixed Quantum-Classical Simulation. J. Am. Chem. Soc. 2011, 133, 5109-5123.

(71) Sekkat, Z.; Yasumatsu, D.; Kawata, S. Pure Photoorientation of Azo Dye in Polyurethanes and Quantification of Orientation of Spectrally Overlapping Isomers. $J$. Phys. Chem. B 2002, 106, 12407-12417.

(72) Grebenkin, S. Y.; Bol'shakov, B. V. Photo Orientation of Azo Dye Molecules in Glassy o-Terphenyl. J. Photochem. Photobiol. A 2006, 184, 155-162.

(73) Meng, X.; Natansohn, A.; Barrett, C.; Rochon, P. Azo Polymers for Reversible Optical Storage. 10. Cooperative Motion of Polar Side Groups in Amorphous Polymers. Macromolecules 1996, 29, 946-952.

(74) Buffeteau, T.; Natansohn, A.; Rochon, P.; Pézolet, M. Study of Cooperative Side Group Motions in Amorphous Polymers by Time Dependent Infrared Spectroscopy. Macromolecules 1996, 29, 8783-8790. 
(75) Wu, S.; Duan, S.; Lei, Z.; Su, W.; Zhang, Z.; Wang, K.; Zhang, Q. Supramolecular Bisazopolymers Exhibiting Enhanced Photoinduced Birefringence and Enhanced Stability of Birefringence for Four-Dimensional Optical Recording. J. Mater. Chem. 2010, 20 .

(76) Vapaavuori, J.; Laventure, A.; Bazuin, C. G.; Lebel, O.; Pellerin, C. Submolecular Plasticization Induced by Photons in Azobenzene Materials. J. Am. Chem. Soc. 2015, $137,13510-13517$.

(77) Laventure, A.; Bourotte, J.; Vapaavuori, J.; Karperien, L.; Sabat, R. G.; Lebel, O.; Pellerin, C. Photoactive/Passive Molecular Glass Blends: An Efficient Strategy to Optimize Azomaterials for Surface Relief Grating Inscription. ACS Appl. Mater. Interfaces 2017, 9, 798-808. 
For Table of Contents use only

\section{Molecular-Level Study of Photo-Orientation in Hydrogen-Bonded Azopolymer Complexes}

Xiaoxiao Wang, Jaana Vapaavuori, C. Geraldine Bazuin, and Christian Pellerin*

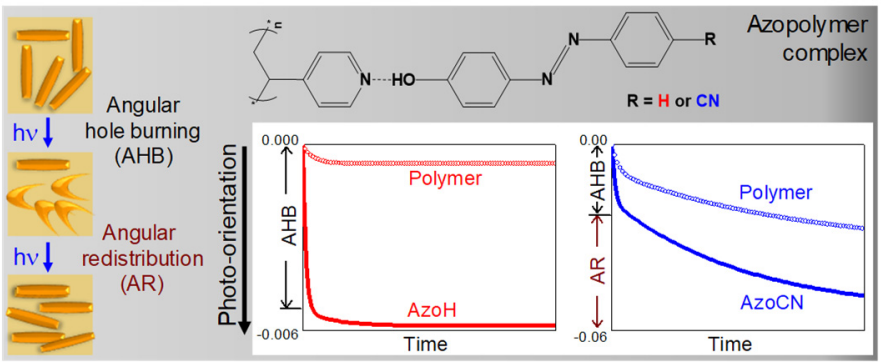

